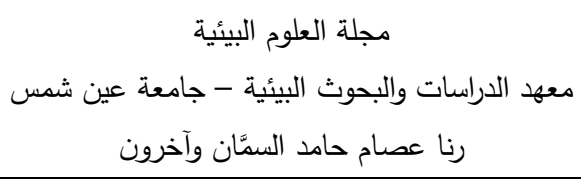

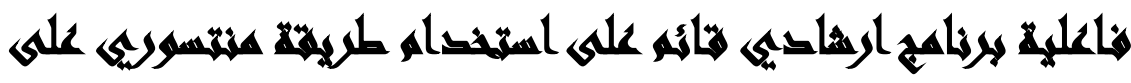

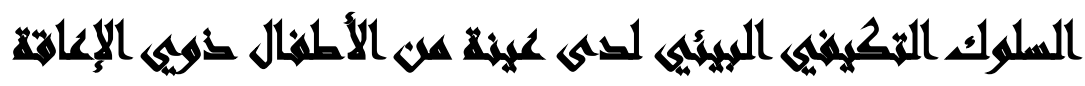

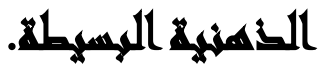

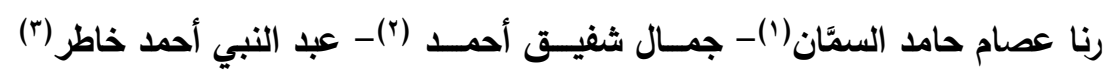

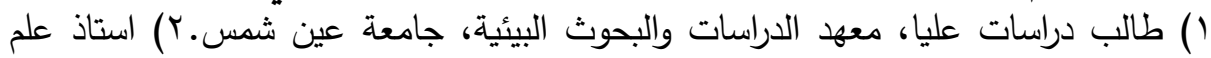

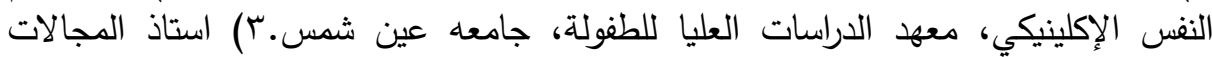
الاجتماعية، ووكيل معهة الخدمة الاجتماعية، القاهرة

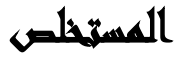

هدفت الدراسة الحالية إلى التعرف على فاعلية برنامج ارشادي قائم على استخدام طريقة

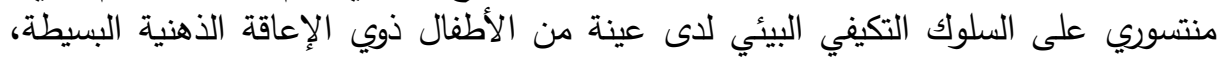

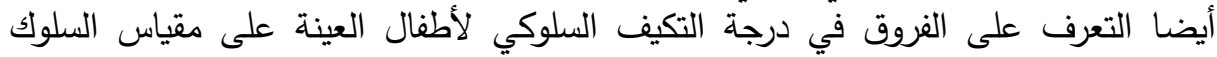

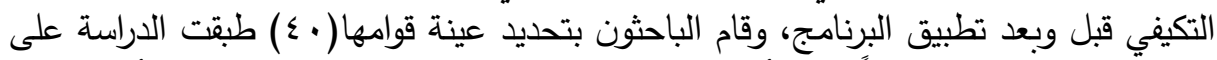

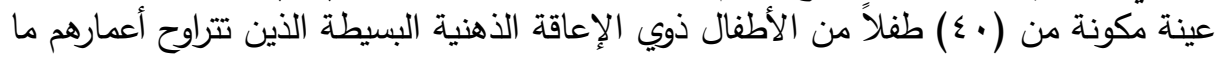

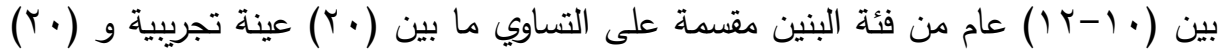

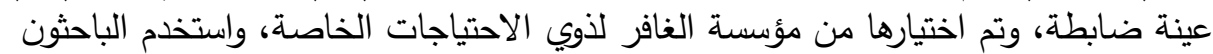

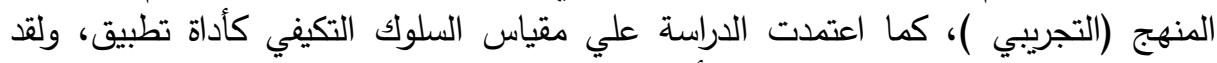

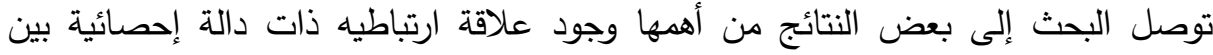

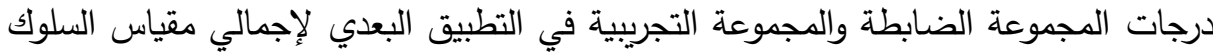

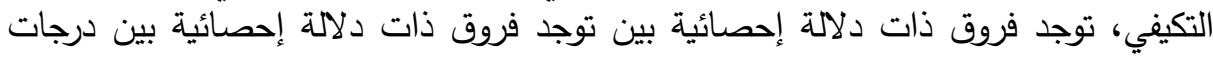

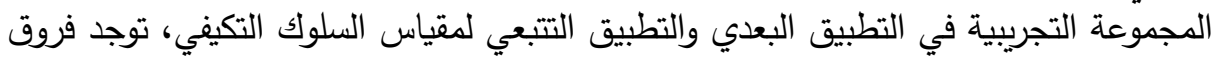

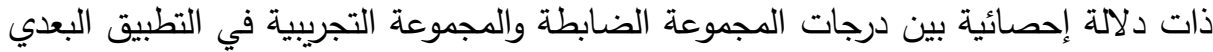

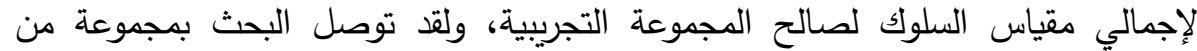

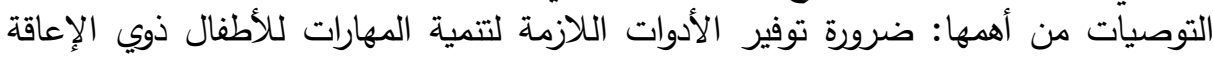
داخل المؤسسات الحكومية، وضع ميزانية خاصة في إدارة كل مؤسسة لغير القادين ماديا، لإنال

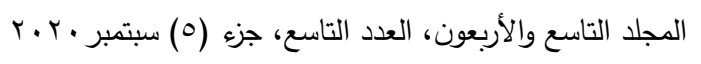


توفير مساحة للتريض يوميا داخل أو بجانب كل مؤسسة، إرسال متخصصين في مجال

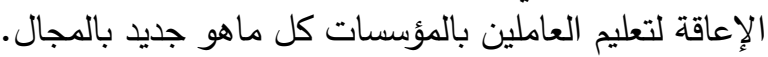

\section{Xaxin}

يمكن القول أن الإعاقة هاجس يلاحق كل المجتمعات لدرجة إن قدر واحكم الأنظمة في

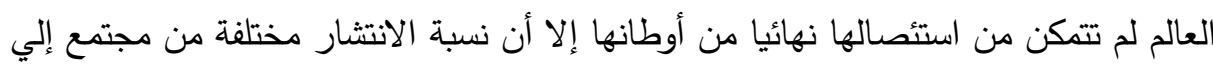

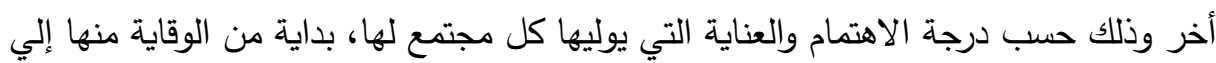

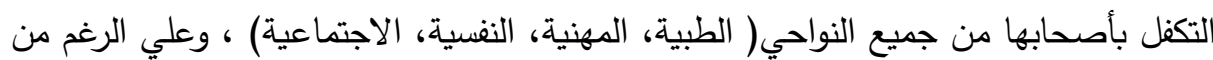
أن المعاقين يشتركون في التسمية إلا أنهم يختلفون في نوع الإعاقة ونسبة انتشارها، كما أنهم

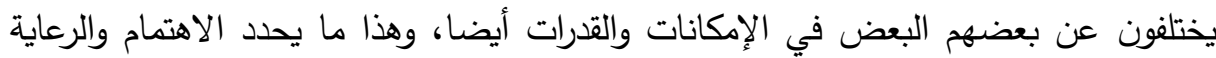
وإن كان الكل له الحق في ذلك، وعليه فنحد هنا بصدد دراسة فئة الإعاقة العقلية البسيطة، وهي فئة قادرة علي التعلم والتطور والبذل إن وجدت برامج ثرية وهادفة تقدم لهم الرعاية

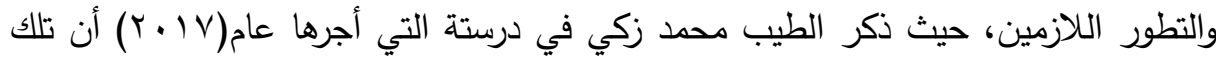
الفئة من الأطفال تعطي نتائج جيدة إذا ما قدم لها برنامج تعليمي مناسبة يلبي احتياجاتهر.

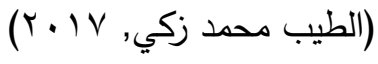

إلي جانب ذلك ذكرت عزة عبد ارحمن في دراستها عام(1) (1) أن هؤلاء الأطفال تحدث لهم بعض التغيرات في بعض الجوانب السمعية والبصرية والتآزر الحركي وذلك من خلال

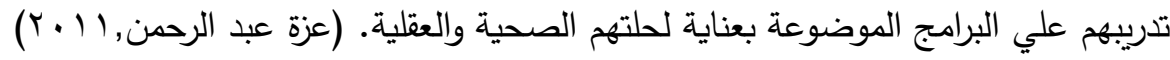
الأمر الذي جعلها محط اهتمام الباحثين والدراسين في مختلف الدجالات الطبية والنفسية والاجتماعية، حيث تم دراسة الإعاقة العقلية لمعرفة تأثيرها علي صاحبها وقدراته وسبل

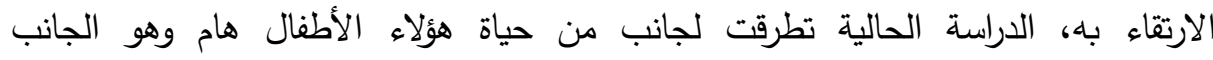

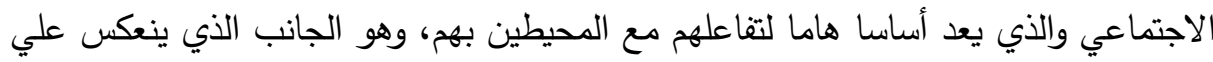
قدرته هؤلاء الأطفال في القيام بمهام الحياة اليومية وممارسة الأنشطة المطلوبة في المجتمع،

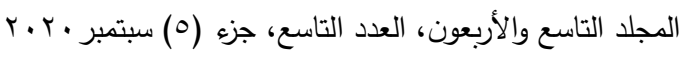

$$
\begin{aligned}
& \text { الترقيم الدولي 0826-1110 }
\end{aligned}
$$


حيث يعد هذا الجانب هو الجانب الهام في قياس التوافق الاجتماعي لهؤلاء الأطفال مع المجتمع والبيئة المحيطة بهم، حيث يقاس التوافق الاجتماعي من خلال المهارات السلوكية والتي يمكن من خلالها إعطاء دلالة حقيقة إذا ما كان سلوك الفرد مرتبطا بعمره الزمني

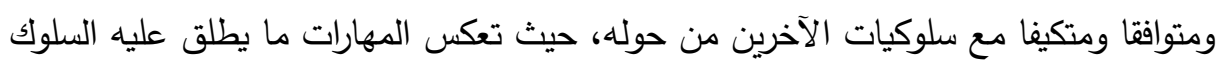
التكيفي الذي يعد المحك الثاني في تثخيص حالات التخلف العقلي حسب تعريف الجمعية

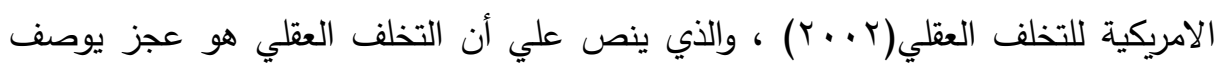
بقصور جوهري وواضح في كل من الأداء الوظيفي والعقلي والسلوك التكيفي، ويظهر جليا في

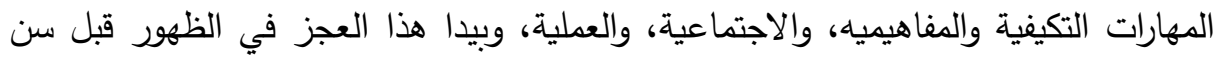

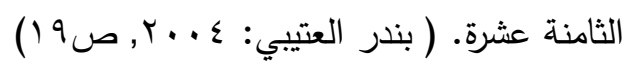

\section{And}

ساعدت زيادة التحضر بصفة خاصة على انتشار المرض والإعاقة نتيجة لشيوع ظاهرة الفقر وما يترتب عليها من أمراض من الممكن أن تؤدي إلى الإعاقة الذهنية والتثخيصات

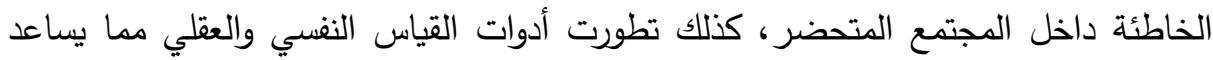
على تحديد مفهوم واضح للإعاقة، فالبعض يعرفها على أنها "الحالة التي تمنع الفرد من القيام

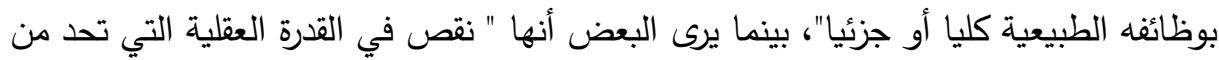

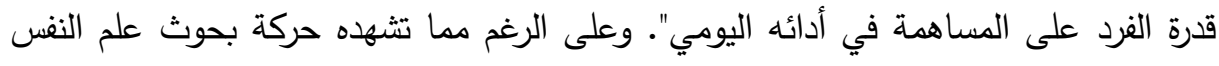
والصحة النفية والإرشاد النفسي في المجتمعات الأجنبية والعربية من كثرة متزايدة ومناحي متعددة تتاولت مشكلة الإعاقة كمشكلة نفسية واجتماعية معقدة على قدر كبير من الأهمية إلاه

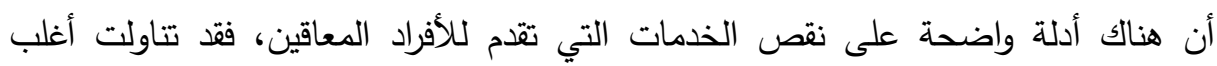
الدراسات المشاكل العامة للأطفال المعاقين وحيث أن المهارات الاستقلالية تمثل واحدة من أهم المشكلات التي تواجه الأطفال ذوي الإعاقة العقلية البسيطة التي تؤثر على كل خبرات التعليم

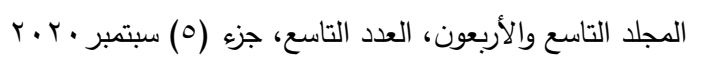


بل تتعكس في شكل اضطرابات سلوكية يلجأ إليها الأطفال هروبا من خبرات الإحباط المتكررة في المواقف التعليمية.

أما عن المؤشرات الخاصة بأعداد المعاقيين داخل جمهورية مصر العربية طبقا للجهاز

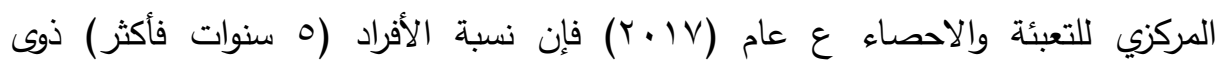

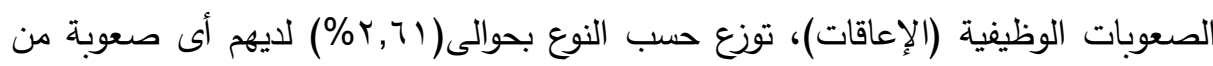

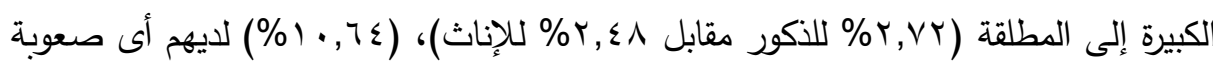

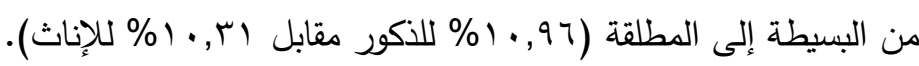
وبالنسبة للأفراد (0 سنوات فأكثر) ذوى الصعوبات الوظيفية وفقا لنوع الصعوبة، فتبلغ

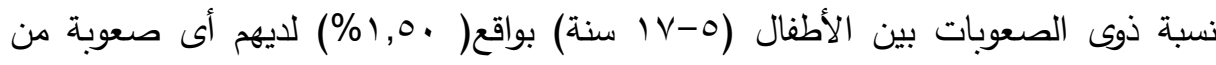

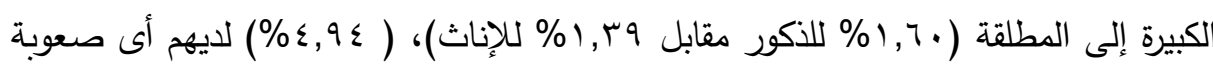

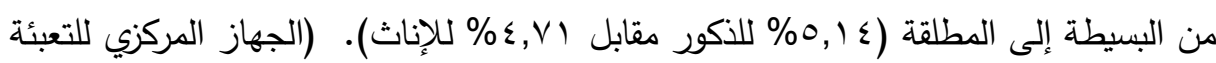
والاحصاء, r.)

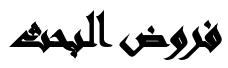

تتبلور فروض البحث في الفروض الآتية: - - توجد فروق دالة إحصائيًا في درجة التكيف السلوكي لأطفال العينة على مقياس السلوك التكيفي قبل وبعد تطبيق البرنامج. - لا توجد فروق دالة إحصائًا في درجة التكيف السلوكي لأطفال العينة على مقياس السلوك التكيفي في التطبيق البعدي والتتبعي. - لا توجد فروق دالة إحصائيًا في درجة التكيف السلوكي لأطفال العينة بين المجموعة الضابطة والمجموعة التجريبية على مقياس السلوك التكيفي في التطبيق البعدي. 


$$
\begin{aligned}
& \text { مجلة العلوم البيئية } \\
& \text { معهد الدراسات والبحوث البيئية - جامعة عين شمس لبئة } \\
& \text { رنا عصام حامد السمَّان وآخرون }
\end{aligned}
$$

\section{أهماهيث المهثد}

$$
\text { تفيد هذه الدراسة في: }
$$

- التعرف على فاعلية برنامج ارشادي قائم على استخدام طريقة منتسوري على السلوك التكيفي البيئي لاى عينة من الأطفال ذوي الإعاقة الذهنية البسيطة.

- التعرف على الفروق في درجة التكيف السلوكي لأطفال العينة على مقياس السلوك الألئل

$$
\text { التكيفي قبل وبعد تطبيق البرنامج. }
$$

- - التعرف على الفروق في درجة التكيف السلوكي لأطفال العينة على مقياس السلوك التكيفي قبل وبعد تطبيق البرنامج.

\section{أهمية المهبه}

\section{ينطوي هذا البحث على أهمية من الناحية النظرية والتطبيقية}

الناحية النظرية:

- - إلقاء الضوء على أهية المهارات الاستقلالية وتأثيرها الإيجابي على جوانب النمو المختلفة لدى الأطفال ذوي الإعاقة الذهنية البسيطة. - عرض فلسفة وفنيات طريقة منتسوري لتنريب الأطفال ذوي الإعاقة العقلية البسيطة. الناحية التطبيقية: - الاستفادة من التحقق من مدى فاعلية برنامج قائم على طريقة منتسوري في تتمية

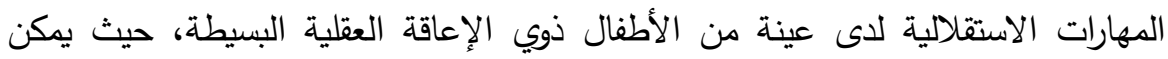

$$
\text { تطبيقه فيما بعد على الحالات المماثلة. }
$$

- إعداد مقياس لتقيييم مهارات الاستقلالية لاى عينة الدراسة ومن ثم يمكن استخدامه لتتييم

$$
\text { المهارات الاستقلالية لاى الحالات الدماثلة. }
$$

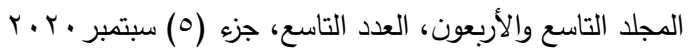

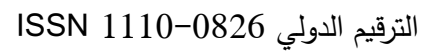


- يمكن أن تكون نتائج هذه الدراسة مرشدا للباحثين على آخرين للاستفادة منها إجراء دراسات قائمة على طريقة منتسوري.

- قد يكون البرنامج المعد مرشدا للقائمين بالعمل مع الأطفال بأهمية برنامج منتسوري في تتمية المهارات الاستقلالية لدى الأطفال ذوي الإعاقة العقلية البسيطة.

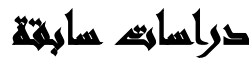

- - دراسة محمد السيد إسماعيل (1 I • Y): بعنوان فاعلية برنامج قائم على طريقة منتسوري لتحسين مهارات السلوك التكيفي لدى عينة من الأطفال ذوي الإعاقة العقلية

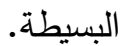

تهذف الدراسة إلي تحسين مهارات السلوك التكيفي (مهارات الرعاية الذاتية) لاى عينة من الأطفال ذوي الإعاقة الذهنية البسيطة. وقد تكونت عينة الدراسة من (7 (1) طفلا من الأطفال ذوي العاقة الذهنية البسيطة (0)

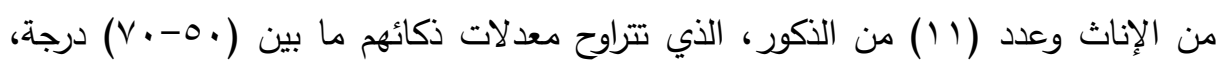
وتتراوح أعمارهم الزمنية ما بين (9-7 (1) سنة، ويتلقون تعليمهم ضمن مركز (أنوار الفكر ) بمنطقة الزاوية الحمرا في محافظة القاهرة، وقد تم تقسيمهم إلى مجموعتين أحدهما تجريبية

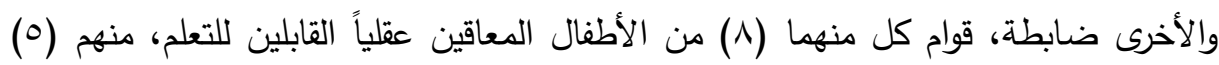

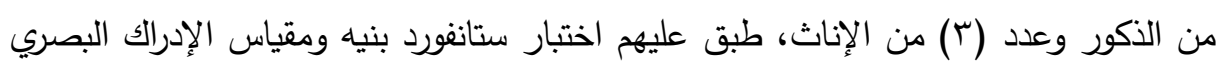
كلأطفال المعاقين عقليا. أشارت النتائج إلى فاعلية البرنامج القائم على طريقة منتسوري لتحسين مهارات السلوك التكيفي (مهارات الرعاية الذاتية) لدى عينة من ذوي الإعاقة الذهنية البسيطة.

$$
\begin{aligned}
& \text { المجلد التاسع والأربعون، العدد التاسع، جزء (0) سبتمبر • r. } \\
& \text { الترقيم الدولي 0826-1110 }
\end{aligned}
$$




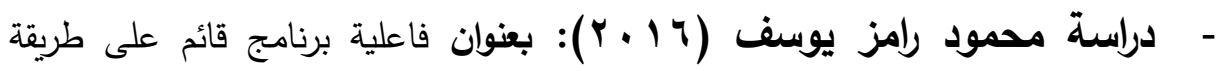
منتسوري لتحسين مهارات السلوك التكيفي لدى عينة من الأطفال المعاقين عقلياً القابلين للتعلم.

تهاف الدارة إلى تحسين مهارات السلوك التكيفي (مهارات الإدراك البصري لدى عينة من

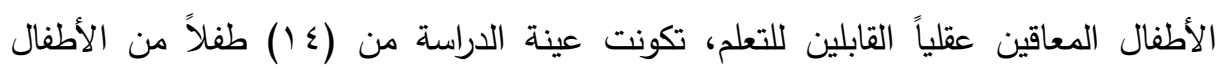

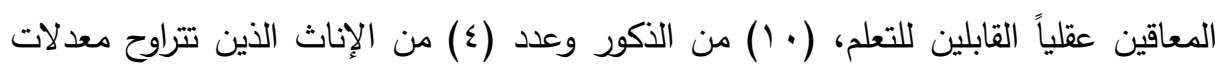

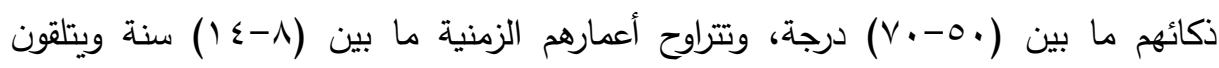

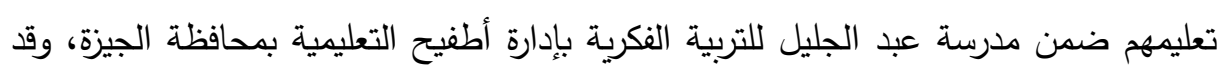
تم تقسيمهم إلى مجموعتين احدهما تجريبية والأخرى ضابطة قوام كل منهما (V) من الأطفال المعاقين عقلياً القابلين للتعلم منهم (0) من الذكور وعدد (r) من الإناث، تتمية المهارات

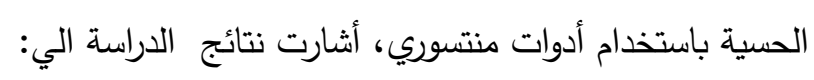

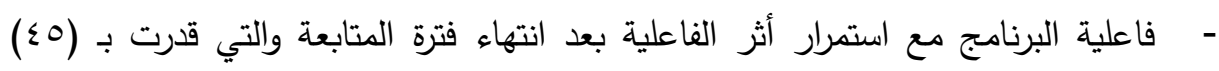
يوماً. - - يختلف كل من تمكين الذات وأساليب المواجهة باختلاف القياسين القبلي والبعدي في

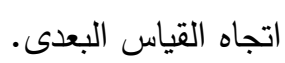

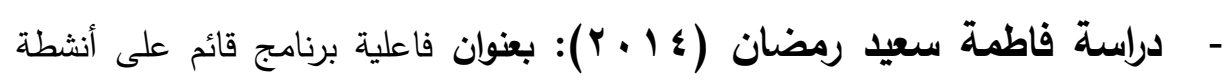
منتسوري لتحسين التوافق النفسي لدى عينة من الأطفال ذوي الإعاقة العقلية.

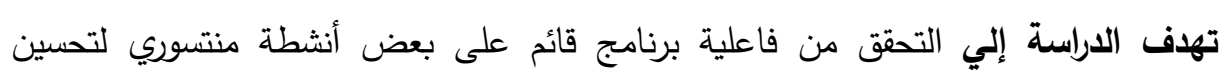

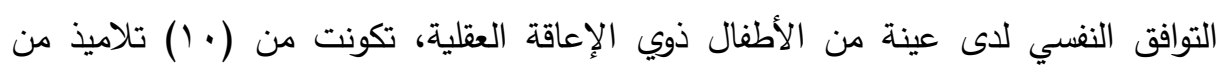

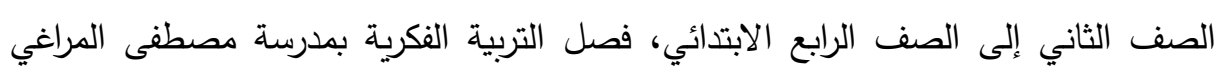
للتعليم الأساسي - القاهرة الجديدة من الذين لديهم مستويات منخفضة من حيث التوافق النفسي التئي

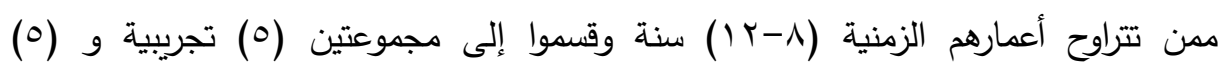


ضابطة، واستخدم الباحث استمارة مقياس ستانفورد بينيه، مقياس التوافق النفسي، برنامج قائم

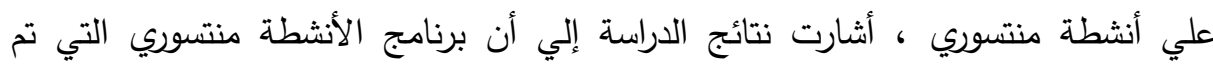

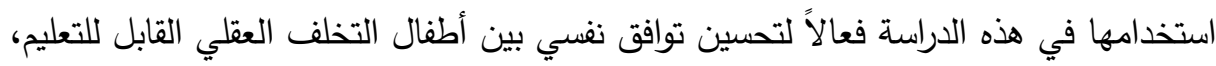
وقد تميز البرنامج عن طريق تواصل فعاليته التي ظهرت من متابعة الدراسة. - دراسة Amy L. Larcinese الأطفال عن تأثير منهجية منتسوري في مرحلة ما قبل المدرسة على المهارات الأكاديمية والاجتماعية. هدفت هذه الدراسة إلى التعرف على تصورات معلمي رياض الأطفال فيما يتعلق بتأثير برامج

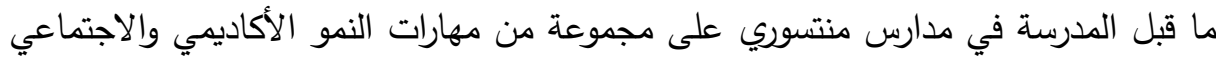

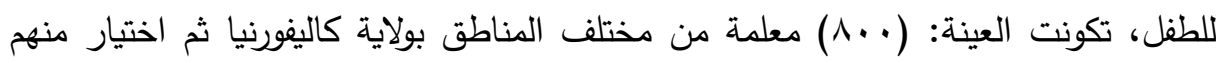

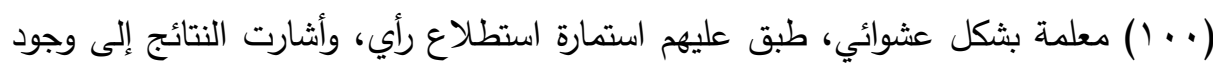
فروق دالة تبين أن المعلمين يؤيدون بشكل ملحوظ منهجية منتسوري في مرحلة ما قبل المدرسة كما أن حصول الطفل على هذه المنهجية يعطيه ميزة أكاديمية واجتماعية عن أقرانهم في نفس المرحلة الذين يفتقرون إلى هذه الخبرة. تتقق الدراسة الحالية مع الدراسات السابقة في الفئة العمرية محل الدراسة حيث اعتمد الدراسات السابقة علي فئات عمرية من (^-7 (1) سنة أي مرحلتي الطفولة والمراهقة، بينما

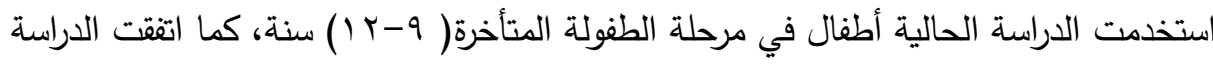

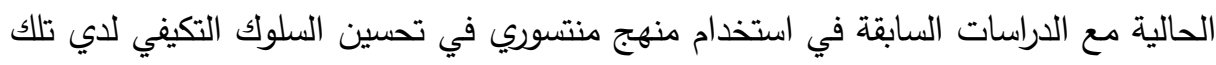
الفئة من الأطفال ذوي الإعاقة العقلية البسيطة ( القابلين للتعلم).

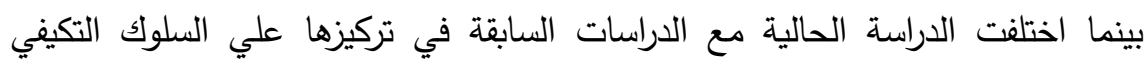
البيئي، بأبعاده الاجتماعية وعلاقة الطفل مع الاخرين من أقرانهم من الأطفال العاديين.

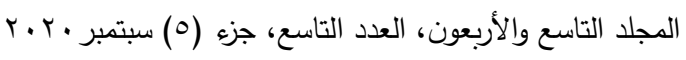

$$
\begin{aligned}
& \text { الترقيم الدولي 0826- ISSN 1110 }
\end{aligned}
$$




\section{مهناهير الهمبث}

( ) البرنامج: هو خطة تتضمن عدة أنشطة لتتمية قدرات الفرد ومهاراته، ويجب أن يهتم البرنامج أن يكون له نشاط وهدف محدد، وأن يراعي التكامل والتتاغم بين الأنشطة.

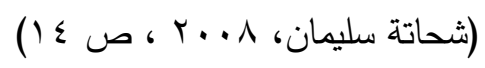

r) الإعاقة الاهنية: الإعاقة العقلية على أنها تلك الإعاقة الناتجة عن عجز التتظيم العقلي والنفسي للفرد عن التكيف الصحي مع بيئته الاجتماعية إلى حد بلوغ مستوى الإع الإسي السلبية الاجتماعية، فهي إعاقة الفرد عن الادراك والتصرف المناسب في المواقف المختلفة

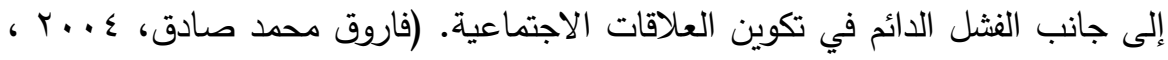

$$
\text { (r.-1 ص }
$$

r) الإعاقة الأهنية البسيطة: هو أداء عقلي عام دون المتوسط ويظهر متلازما مع

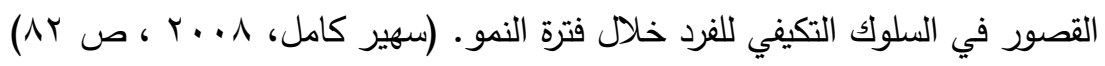

\section{الاسار اللنظاري اللهمشه}

\section{تصنيف الإعاقة حسب السلوك التكيفي: Sociological Classification:} هو نوع من تصنيف الإعاقة يقوم علي محك التكيف الاجتماعي للفرد، ومدي اعتماده علي نفسه والتزامه بالمطالب الاجتماعية المكلف بها، فعلي سييل المثال إخفاق الطفل في أن يحقق الاعق النضج الطبيعي في المهارات الحركية لمن هم في مثل سنة في السنوات التي تسبق دخول المدرسة، قد يعني هذا الأمر بوجود إعاقة ذهنية لدي الطفل. Hardiman, Sharon )

كذلك عجزه عن مواصلة تعليمة في المواقف العادية وإخفاقه الاكاديمي المستمر، قد يعتبر محكا للدلالة علي الإعاقة الذهنية في هذه المرحلة، أيضا فثلة في مسايرة الأعراف التي

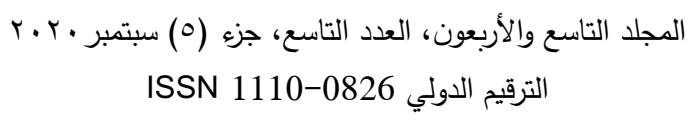


تحيط به وفي تكوين علاقات شخصية مع الآخرين خلال مرحلة الرشد. (فاروق الروسان, (70 r...

وهنا نري أن أحد أهداف التربية الخاصة بمفهومها الحديث رعاية الثخص المعاق ذهنيا

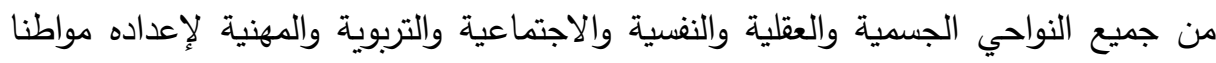

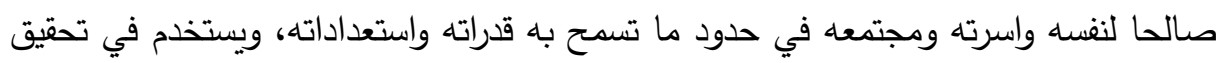
هذا الهدف الكبير العديد من برامج الرعاية الاسرة ومعاهد وبرامج التربية والتأهيل المهني

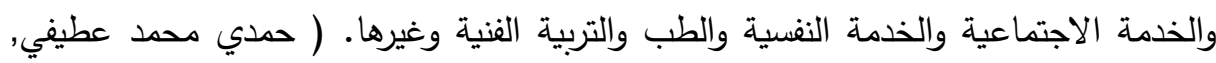
(r $r, r \cdot 0$ ومن هنا نري أن العلماء يتقون علي أن توفير الرعاية الخاصة لحالات الإعاقة الذهنية

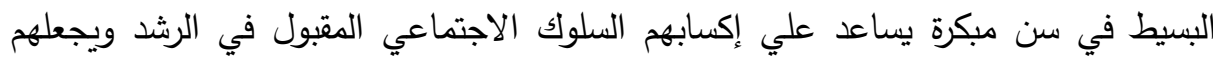
يعيشون حياتهم الاجتماعية كإقرانهم غير المعاقين، وجعلهم مقبولين اجتماعيا من أسرهم

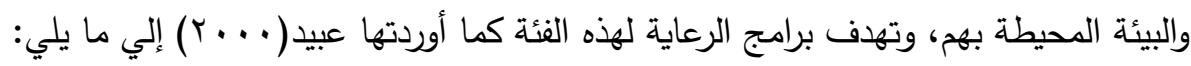
- تعليمهم القراءة والكتابة والحساب، مما يساعدهم علي محو أميتهم في حدود قدراتهم

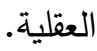

- إكسابهم السلوكيات المقبولة اجتماعيا في رعاية أنفسه والاعتماد علي النفس وتحمل المسئولية في الأسرة والعمل والمجتمع، مما يجعلهم يعيشون الحياة الاجتماعية كالعاديين في الانتقال والبيع والثراء والتعامل بالعملة والترفيه عن النفس. - تعليمهم العبادات والمعاملات في ضوء معتقدات أسرهم ومجتمعهم، مما جعلهم يمارسون

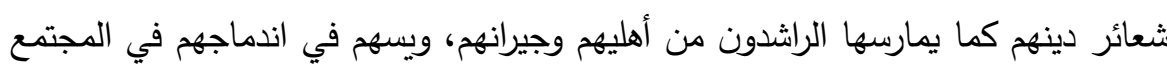
في مواقف العبادات والمعاملات في الحياة اليومية. - زيادة حصيلتهم اللغوية وتحسين قدراتهم علي النطق والكلام، مما يجعلهم قادرين علي التعبير عن أنفهم والتواصل مع الآخرين. 
- تأهيلهم مهنيا وتدريبهم علي مهنة من المهن الحسية في المجتمع في ضوء قدراتهم العقلية وميولهم المهنية ومطالب سوق العمل في المجتمع.

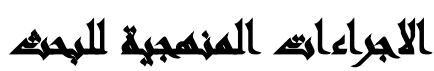

استخدمت الدراسة الحالية المنهج "ثبه التجريبي" اعتمد الباحث في هذه الدراسة المنهج الثبه تجريبي وأسلوب الدراسة الميدانية، الذي أمكن من خلاله جمع المعلومات والبيانات اللازمة للإجابة عن فروض البحث وتحقيق أهدافه، وذلك بالرجوع إلى أدبيات التربية

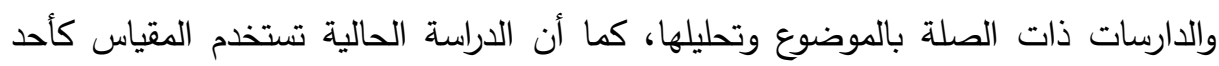

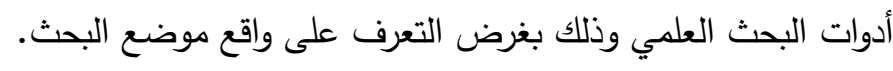

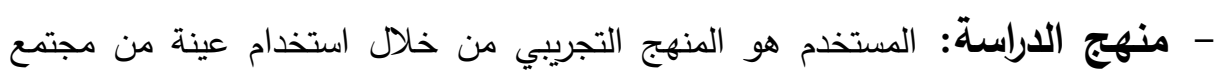
الدراسة لبعض الأطفال ذوي الإعاقة العقلية البسيطة. - أدوات الدراسة: استخدم الباحثون مقياس السلوك التكيفي( الفانلانيد)، وبرنامج ماريا منتسوري

قام الباحثون باستخدام مصدرين أساسين للمعلومات:( ) المصادر الثانوية: والتي تتمثل في الكتب والمراجع العربية والأجنبية ذات العلاقة والدوريات والمقالات والتقارير ، والأبحاث والدارسات السابقة التي تتاولت موضوع البحث والمطالعة في مواقع الانترنت المختلفة. r) المصادر الأولية: والتي تمثلت في جمع البيانات الأولية من خلال اختبار الفانلانيد كاداه

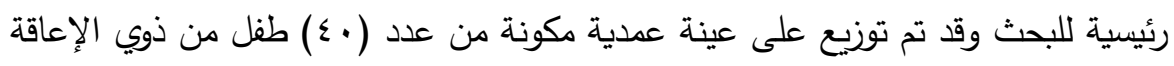
الذهنية البسيطة. r) وصف أداة القياس: قام الباحثون بتطبيق السلوك التكيفي(الفاينلاند) للأطفال ذوي الإعاقة

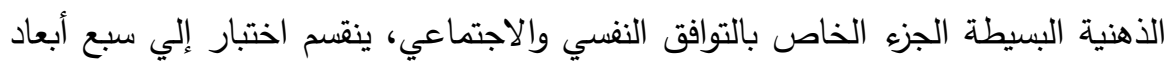

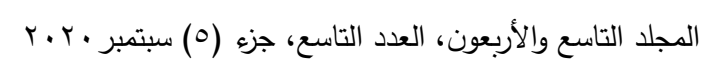

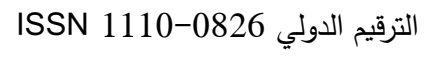


أساسية يشمل البعد الأول سلوك التمردي، ويشمل البعد الثاني قياس الانسحاب

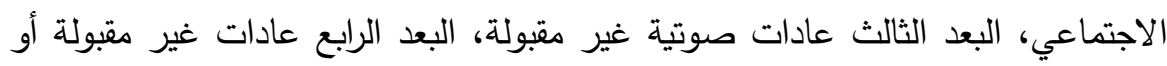

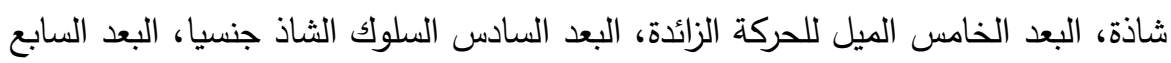

الاضطرابات الانفعالية والنفسية.

وقد قام الباحثون بعمل صدق وثبات للأدوات في ضوء عينة الدراسة الحالية :

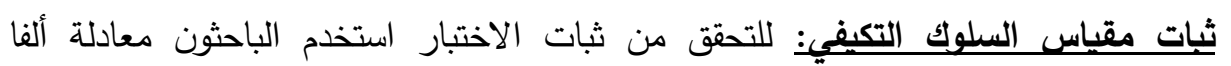
كرونباخ (Alpha Cronbach)، ويوضح الجدول التالي معاملات الثبات الناتجة باستخدام

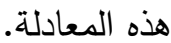

جدول(1 ) : ثبات عبارات مقياس السلوك التكيفي

\begin{tabular}{|c|c|c|}
\hline قيمة آلفا & عدد العبارات & آبعاد مقياس \\
\hline$\cdot, 7) \leq$ & 0 & السلوك المدمر والعنيف \\
\hline$\cdot, 9 \cdot 0$ & 7 & السلوك المضاد للمجتمع \\
\hline$\cdot, \wedge \vee 7$ & 7 & سلوك التمرد \\
\hline$\cdot, 7 \vee \varepsilon$ & r & سلوك لا يوثق به \\
\hline$\cdot, \mathrm{VOV}$ & $r$ & الانسحاب \\
\hline., $09 \mathrm{Y}$ & r & السلوك النمطي واللزمات الغرببة \\
\hline-- & $T$ & السلوك غير مناسب في العلاقات الاجتماعية \\
\hline-- & 1 & عادات صوتية غير مقبولة \\
\hline$\cdot, \wedge \circ \mathrm{r}$ & $\varepsilon$ & عادات غير مقبولة آو شاذة \\
\hline-- & 1 & سلوك يؤذي النفس \\
\hline-- & 1 & الميل للحركة الزائدة \\
\hline$\cdot, \vee \vee \wedge \varepsilon$ & $\varepsilon$ & السلوك الشاذ جنسيا \\
\hline$\cdot, \wedge 91$ & $\mathrm{~V}$ & الاضطرابات الانفعالية والنفسية \\
\hline-- & 1 & معلومات تكميلية \\
\hline$\cdot, 971$ & $\varepsilon 0$ & إجمالى مقياس السلوك التكيفي \\
\hline
\end{tabular}

يتضح من الجدول السابق لثبات عبارات مقياس السلوك التكيفي أن قيم معامل ألفا

( )

(التعبير الإنفعالي، الحساسية الإنفعالية، الضبط الإنفعالي، التعبير الاجتماعي، الحساسية

192

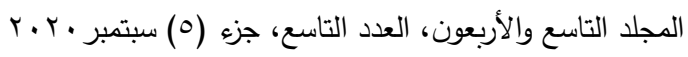

$$
\begin{aligned}
& \text { الترقيم الدولي 0826-1110 }
\end{aligned}
$$


الاجتماعية، الضبط الاجتماعي، المراوغة الاجتماعية، إجمالي مقياس السلوك التكيفي) على التوالي، وهي قيم جميعها تؤكد على ثبات المقياس لكونها أعلى من (0, • •).

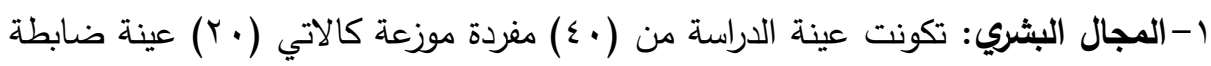

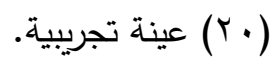

r-المجال المكاني: منطقة القاهرة حيث تم اختيار عينة من ذوي الإعاقة الذهنية البسيطة بمؤسسة الغافر لذوي الاحتياجات الخاصة (إقامة دائمة) بمنطقة عين شمس.

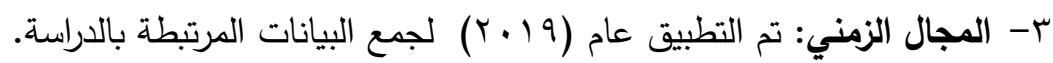
ع-شروط العينة: قد أخذ الباحثون عينة عمدية مقصودة من الأطفال ذوي الإعاقة الذهنية البسيطة

وقد راعت الدراسة الثروط التالية: ا ـ أن تضم العينة أطفال من فئة الإعاقة الذهنية البسيطة.

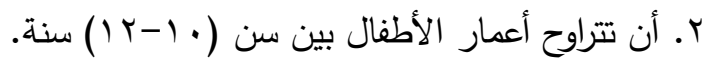
r. أن تكون نسبة الذكاء لا تقل عن معدل البسيط. - خصائص عينة الاراسة:

\begin{tabular}{|c|c|c|c|c|c|c|}
\hline \multicolumn{2}{|c|}{ إجمالى العينة } & \multicolumn{2}{|c|}{ المجموعة التجرببية } & \multicolumn{2}{|c|}{ المجموعة الضابطة } & \multirow[b]{2}{*}{ المتغيرات } \\
\hline الأمعياري & الحسابي & الإلمعياري & الحسابي & المعياري & الكسابي & \\
\hline$\cdot, \mathrm{\vee} \wedge$ & 11,11 & $\cdot, \wedge \Gamma$ & $11, r$. & $\cdot, \mathrm{VO}$ & 11,10 & السن \\
\hline $1, \cdot 7$ & $r, \ldots$ & 1,19 & $r, .0$ & $\cdot, 9 \leqslant$ & $r$, & الترتيب فى فى \\
\hline
\end{tabular}

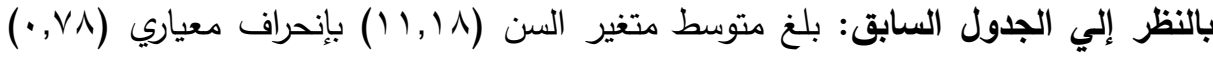

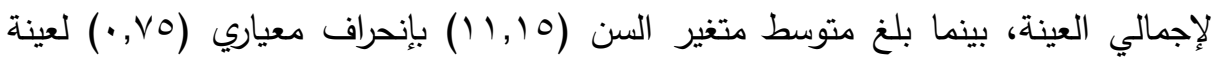

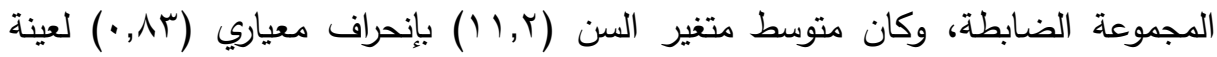
المجموعة التجريبية.

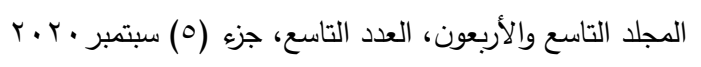
الترقيم الدولي 0826- ISSN 1110 


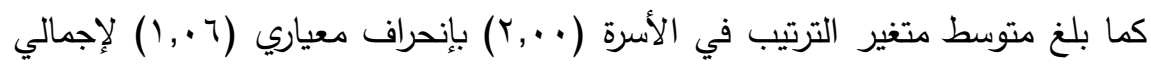

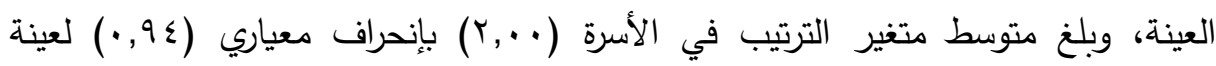
المجموعة الضابطة، وكان متوسط متغير الترتيب في الأسرة (ب, ب) بإنحراف معياري (19 (1, (1) لعينة المجموعة التجريبية.

الوصف العام للبرنامج وموضوعاته: البرنامج: يتحدد مفهوم البرنامج التدريبي الحالي: علي أنه برنامج مخطط ومنظم في ضوء أسس علمية ويتضمن استخدام مجموعة من الأنشطة والفنيات بهدف تحسين السلوك التكيفي وخفض مشكلات السلوك التكيفي لدي عينة من الأطفال ذوي الإعاقة العقلية البسيطة المترددين علي مؤسسة الرعاية. أولا: فلسفة البرنامج: تعتبر مرحلة الطفولة من أهم مراحل النمو وأكثرها إسهاما في حياة الأطفال عامة والأطفال المعاقين عقليا خاصا، فهي تعتبر العمر الأمثل لتعليم وتتمية المهارات المختلفة التي يمكن أن تساعد الطفل علي التكيف مع الواقع وتزيد من فاعلية مشاركته في

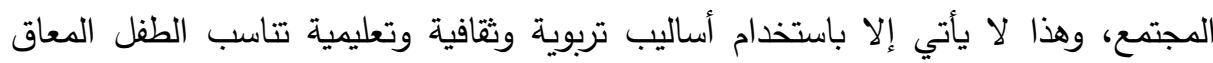

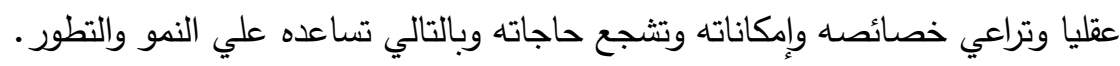
وفي ضوء ما سبق تتلخص فلسفة البرنامج الحالي فيما يلي: - اعتبار الطفل المعاق عقليا ذوي مشكلات السلوك التكيفي هو المحور الأساسي، ولذلك تم تصميم جلسات البرنامج لتناسب احتياجاته، ولكي تكون ذات فائدة تعود علي سلوكيات

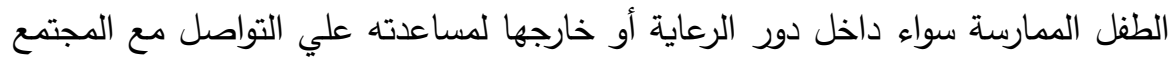

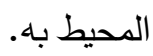

- إكسابه الأنماط السلوكية السوية المقبولة اجتماعيا وذلك من خلال تطبيق الأنشطة الخاصة بمنهج ماريا منتسوري.

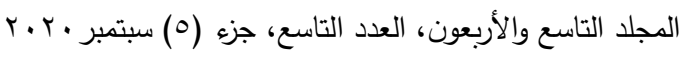

$$
\begin{aligned}
& \text { الترقيم الدولي 0826-1110 }
\end{aligned}
$$


- تقديم مجموعة من الأنشطة التي تتتاسب مع طبيعة المشكلات السلوكية التي يعاني منها

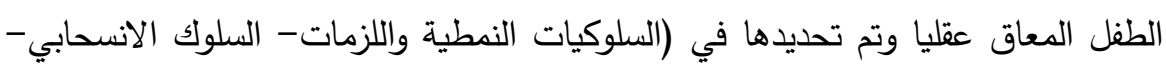
إيذاء الذات- التمرد- العادات الثاذة الغير مقبولة) - استخدام الأدوات والخامات الامنة المتوفرة في البيئة التي يعيش فيها الطفل المعاق ذهنيا حتي يستطيع أن يتعامل معها. - ولذلك تم إعداد البرنامج لكي يساعد في تعديل وتحسين حدة مشكلات السلوك التكيفي التي

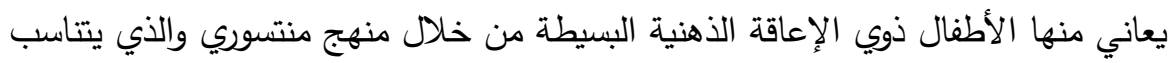

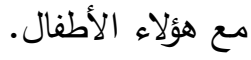
ثانيا: تعريف البرنامج: عرف الباحثون البرنامج الحالي: بأنه" خطة منظمة تتضمن مجموعة من الأنشطة التعليمية الخاصة بمنهج ماريا منتسوري لتحسين السلوك التكيفي لدي ليك مجموعة من الأطفال ذوي الإعاقة العقلية البسيطة الذين يعانون من بعض مشكلات السلوك

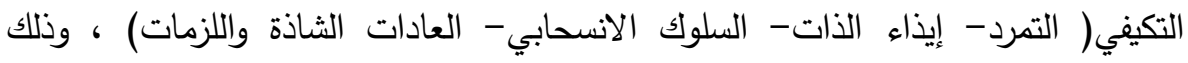
باستخدام بعض أنشطة المنهج من أجل تحسين المشكلات السلوكية خلال فترة زمنية محددة.

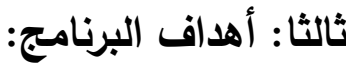
• الهاف العام: يهدف البرنامج الحالي إلي محاولة التخفيف من حدة بعض مشكلات السلوك التكيفي ( التمر - إيذاء الذات- السلوك الانسحابي) التي يعاني منها الأطفال

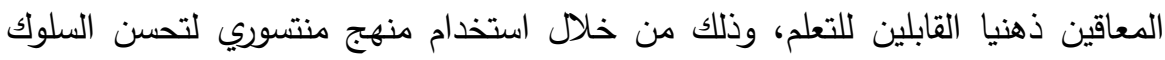

\section{التكيفي. \\ الأهداف الإجرائية للبرنامج:}

وتضم أهداف معرفية ومهاريه ووجدانية يمكن إجمالها فيما يلي:

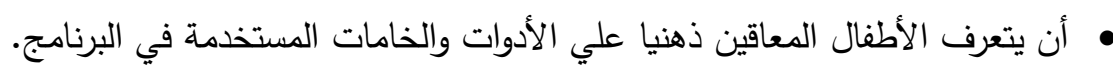

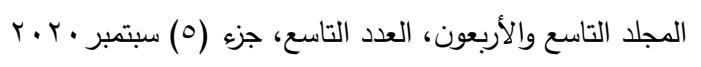

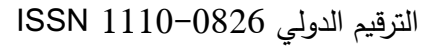


• أن يكتسب الأطفال المعاقين ذهنيا المهارات الحركية اللازمة لمساعدتهم علي استخدام

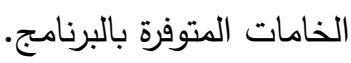

• أن ينفس الأطفال المعاقين عقليا عن رغباتهم ونزعاتهم التخريبية وانفعالاته ومشكلاتهم بلتهات بطريقة ايجابية ومقبولة

• أن يلتزم الأطفال المعاقين عقليا بالقواعد والتعليمات عن ممارسة الأنثطة.

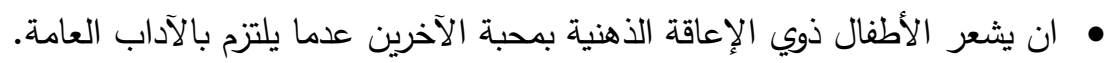

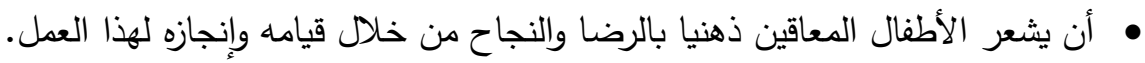
• • ان يشارك الطفل المعاق ذهنيا في أنثطة تساعده علي التألف والتقارب.

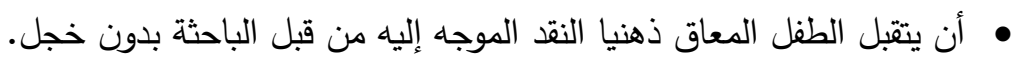
رابعاً: لمن يقدم البرنامج: تم تحديد خصائص الفئة المستخدمة في البرنامج علي النحو لئل • تم وضع برنامج تحسين السلوك التكيفي لمجموعة من الأطفال المعاقين ذهنيا من ذوي الإعاقة الذهنية البسيطة الذين يعانون من مشكلات في السلوك التكيفي، والذين تتراوح

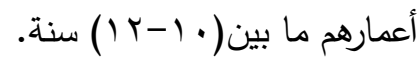
• مراعاة التجانس بين أطفال المجموعة التجريبية والضابطة من حيث العمر الزمني، نسبة

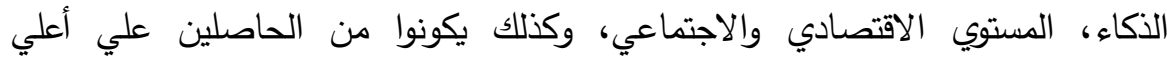
الدرجات علي مقياس السلوك التكيفي. • • المدة الزمنية للبرنامج ومكان انعقاد الجلسات:

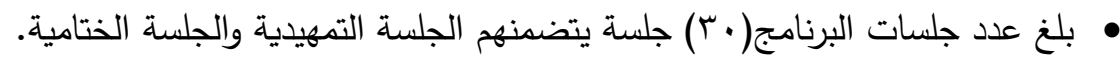




$$
\begin{aligned}
& \text { مجلة العلوم البيئية } \\
& \text { معهد الدراسات والبحوث البيئية - جامعة عين شمس له } \\
& \text { رنا عصام حامد السمّان وآخرون }
\end{aligned}
$$

\begin{tabular}{|c|c|c|c|c|}
\hline 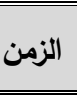 & الأداة المستخدمة & عنوان الجلسة & الجلسة & الاسبوع \\
\hline $\begin{array}{l}\leqslant 0 \\
\leqslant 0 \\
\leqslant 0\end{array}$ & أدوات منتسوري مجموعة السجاب وتركيب الصغير & جلسة تعارف للأولياء المور & 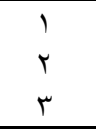 & 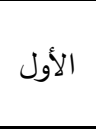 \\
\hline $\begin{array}{l}\leqslant 0 \\
\leqslant 0 \\
\leqslant 0\end{array}$ & 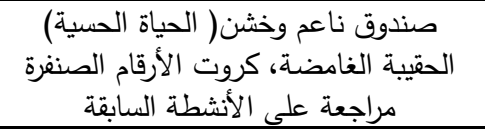 & تتمية مدي الانتباه اللمسي & $\begin{array}{l}\varepsilon \\
0 \\
1\end{array}$ & 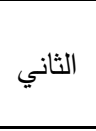 \\
\hline $\begin{array}{l}\leqslant 0 \\
\leqslant 0 \\
\leqslant 0 \\
\leqslant 0\end{array}$ & 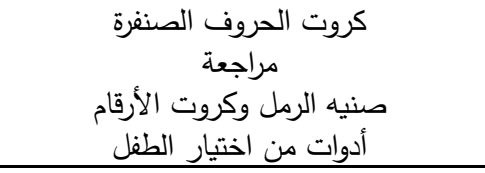 & تتمية مدي الانتباه اللمسي & $\begin{array}{l}v \\
1 \\
q \\
1 .\end{array}$ & 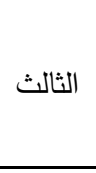 \\
\hline $\begin{array}{l}\leqslant 0 \\
\leqslant 0 \\
\leqslant 0\end{array}$ & 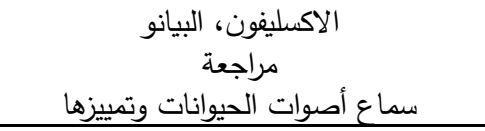 & تنمية مدي الانتباه السمعي & $\begin{array}{l}11 \\
11 \\
11\end{array}$ & 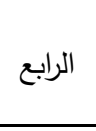 \\
\hline $\begin{array}{l}\leqslant 0 \\
\leqslant 0 \\
\leqslant 0\end{array}$ & صندوق الأصوات & تنمية مدي الانتباه السمعي & $\begin{array}{l}1 \leq \\
10 \\
17\end{array}$ & 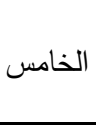 \\
\hline $\begin{array}{l}\leqslant 0 \\
\leqslant 0 \\
\leqslant 0\end{array}$ & 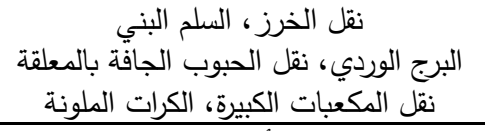 & تتمية مدي الانتباه البصري & $\begin{array}{l}18 \\
11 \\
19 \\
\end{array}$ & 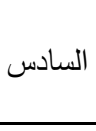 \\
\hline$\varepsilon 0$ & مراجعة أنثطة الجلسة & تنمية مدي الانتباه البصري & $r \cdot$ & السابع \\
\hline $\begin{array}{l}\leqslant 0 \\
\leqslant 0 \\
\leqslant 0\end{array}$ & 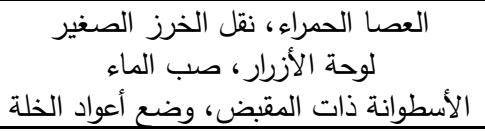 & & 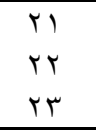 & \\
\hline $\begin{array}{l}\leqslant 0 \\
\leqslant 0 \\
\leqslant 0\end{array}$ & 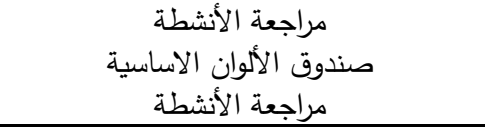 & تتمية مدي الانتباه البصري & $\begin{array}{l}r \leq \\
r 0 \\
r y\end{array}$ & 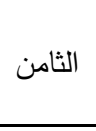 \\
\hline $\begin{array}{l}\leqslant 0 \\
\leqslant 0 \\
\leqslant 0\end{array}$ & نقل المياه بالسرنجة، مطابقة الرقم مع العدد & تنمية مدي الانتباه البصري & $\begin{array}{l}r V \\
r A\end{array}$ & 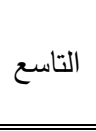 \\
\hline
\end{tabular}

\section{خامساً: المدة الزمنية للبرنامج ومكان انعقاد جلساته: جدول رقم (7 () بلغ عدد}

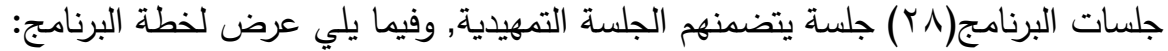

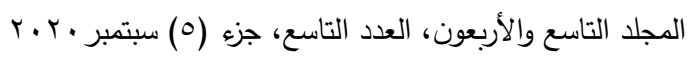


مجلة العلوم البيئية

معهد الدراسات والبحوث البيئية - جامعة عين شمس لبنه

رنا عصام حامد السمَّان وآخرون

\section{نمثائي المهيد}

الفرض الاول: توجد فروق دالة إحصائيًا في درجة التكيف السلوكي لأطفال العينة على مقياس السلوك التكيفي قبل وبعد تطبيق البرنامج. جدول(r): نتائج اختبار (ويلكوكسون) لحساب الفروق بين درجات التكيف السلوكي لأطفال العينة على مقياس السلوك التكيفي قبل وبعد تطبيق البرنامج.

\begin{tabular}{|c|c|c|c|c|c|c|}
\hline \multirow{2}{*}{ مستوى الدلاية } & \multirow{2}{*}{ (Z) } & \multicolumn{2}{|c|}{ 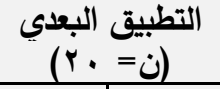 } & \multicolumn{2}{|c|}{ التطبيق القبلى } & \multirow{2}{*}{ المتغيرات } \\
\hline & & مجموع الزتب & متوبط الرتب & مجموع الرتب & متوبط الرتب & \\
\hline 1 ...,. د دالة & r,qYo- & $\cdot, \cdots$ & $\cdot, \cdots$ & $r 1 \cdot, \cdots$ & $1 \cdot, 0$ & السلوك المدمر والعنيف \\
\hline | (.,., دالة & r,qYr- & $\cdot, \cdots$ & $\cdot, \cdots$ & $r) \cdot, \cdots$ & $1 \cdot, 0$ & السلوك المضـاد للمجتمع \\
\hline 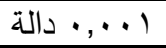 & r,qrV- & $\cdot, \cdots$ & $\cdot, \cdots$ & $Y r_{1}, \ldots$ & $1 \cdot, 0$ & سلوك التمرد \\
\hline 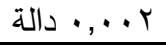 & $r, \cdot q \cdot-$ & $\cdot, \cdots$ & $\cdot, \cdots$ & $\vee \wedge, \cdots$ & $7,0$. & سلوك لا يوثق به \\
\hline 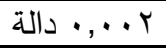 & $r, \cdot 7 \Lambda-$ & $\cdot, \cdots$ & $\cdot, \cdots$ & $\vee \wedge, \cdots$ & 7,0 . & الإنسحاب \\
\hline 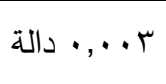 & $r, \ldots r-$ & $\cdot, \cdots$ & $\cdots$ & $77, \cdots$ & $7, \cdots$ & السلوك النمطي واللزمات \\
\hline ץ • •, •• دالة & $r, \ldots r-$ & $\cdot, \cdots$ & $\cdot, \cdots$ & $77, \cdots$ & $7, \cdots$ & السلوك غير مناسب في الاجتماعية \\
\hline | ...,. د دالة & r, $\leq q \mu-$ & $\cdot, \cdots$ & $\cdot, \cdots$ & $1 Y \cdot, \ldots$ & $\Lambda, \cdots$ & عادات صوتية غير مقبولة \\
\hline 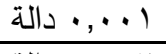 & $\Gamma, \wedge \leq 0-$ & $\cdot, \cdots$ & $\cdot, \cdots$ & $19 \cdot, \cdots$ & $1 \cdot, \cdots$ & عادات غير مقبولة أو شاذة \\
\hline 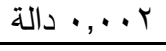 & r,ו & $\cdot, \cdots$ & $\cdot, \cdots$ & $\vee \wedge, \cdots$ & 7,0 & سلوك يؤذي النفس \\
\hline 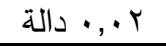 & $r, \Sigma) \cdot-$ & $\cdot, \cdots$ & $\cdot, \cdots$ & $r \wedge, \cdots$ & $\varepsilon, \cdots$ & الميل للحركة الزائدة \\
\hline 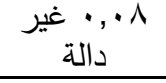 & 1,VMr- & $\cdot, \cdots$ & $\cdot, \cdots$ & $7, \cdots$ & $r, \ldots$ & السلوك الشاذ جنسياً \\
\hline 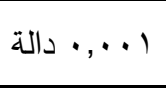 & $r, T r \leq-$ & $\cdot, \cdots$ & $\cdot, \cdots$ & 10r,. & $9, \ldots$ & الإضطرابات الإنفعالية \\
\hline ^ر, • غير & $\cdot, Y M V-$ & $\cdot, \cdots$ & $\cdot, \cdots$ & $V Y, O$. & $9, \cdot 7$ & معلومان: \\
\hline ا . .,.• دالة & $r, q r .-$ & $\bullet, \cdots$ & $\cdot, \cdots$ & Yl., . & $1 \cdot, 0$ & إجمالى مقياس السلوك \\
\hline
\end{tabular}


من الجدول السابق لنتائج العلاقة ارتباطية الضغوط البيئية والتكيف يتضح التالي: > توجد فروق ذات دلالة إحصائية بين درجات المجموعة التجريبية في التطبيق القبلي

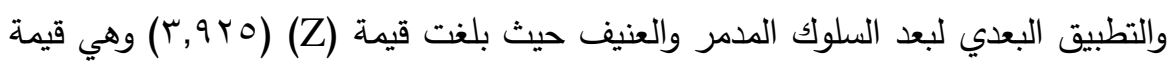

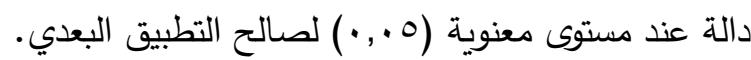
> توجد فروق ذات دلالة إحصائية بين درجات المجموعة التجريبية في التطبيق القبلي

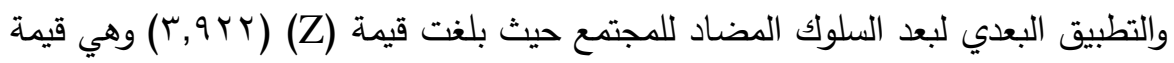
دالة عند مستوى معنوية (0. . • ) لصالح التطبيق البعدي. > توجد فروق ذات دلالة إحصائية بين درجات المجموعة التجريبية في التطبيق القبلي

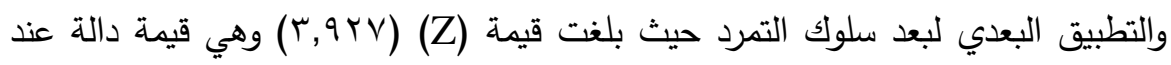

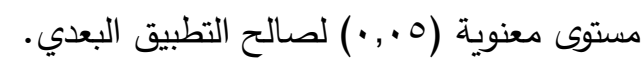
> توجد فروق ذات دلالة إحصائية بين درجات المجموعة التجريبية في التطبيق القبلي

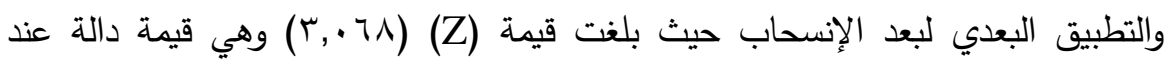

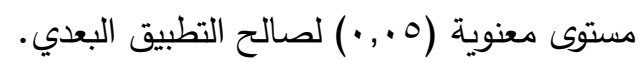
> توجد فروق ذات دلالة إحصائية بين درجات المجموعة التجريبية في التطبيق القبلي

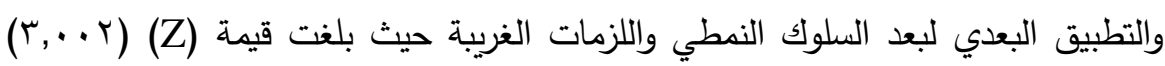
وهي قيمة دالة عند مستوى معنوية (0 . . •) لصالح التطبيق البعدي. > توجد فروق ذات دلالة إحصائية بين درجات المجموعة التجريبية في التطبيق القبلي

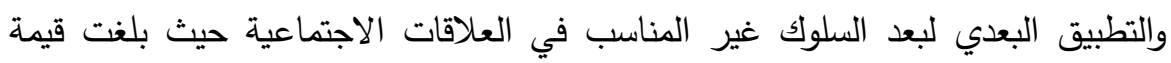

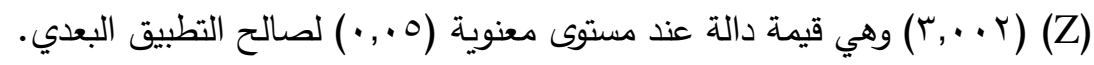
> توجد فروق ذات دلالة إحصائية بين درجات المجموعة التجريبية في التطبيق التبلي

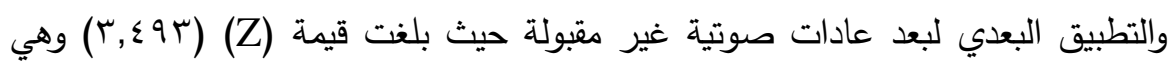

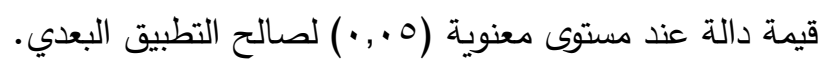


توجد فروق ذات دلالة إحصائية بين درجات المجموعة التجريبية في التطبيق التبلي

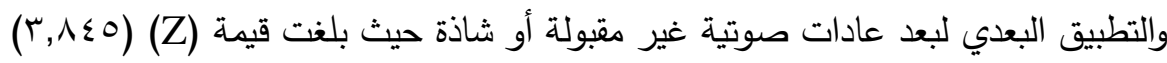

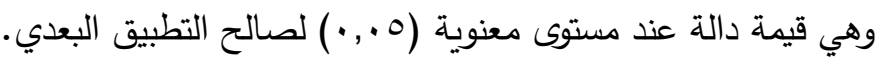
توجد فروق ذات دلالة إحصائية بين درجات المجموعة التجريبية في التطبيق القبلي

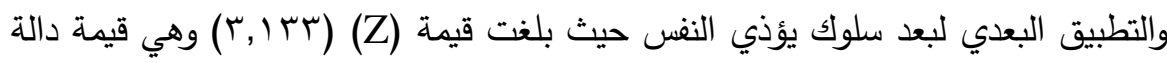
عند مستوى معنوية (0. . • ) لصالح التطبيق البعدي. لا توجد فروق ذات دلالة إحصائية بين درجات المجموعة التجريبية في التطبيق القبلي

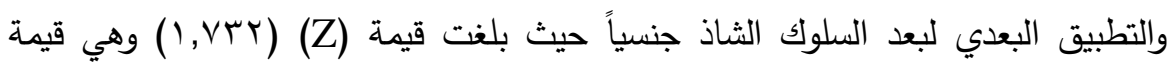
غير دالة عند مستوى معنوية (0. . • ) لصالح التطبيق البعدي. توجد فروق ذات دلالة إحصائية بين درجات المجموعة التجريبية في التطبيق القبلي

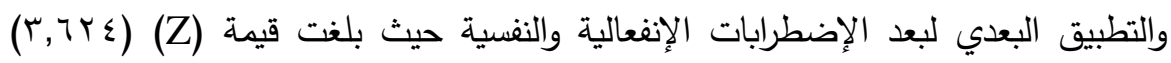

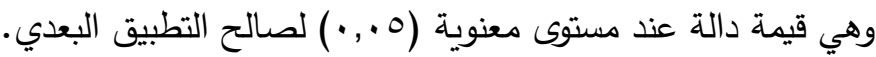
> لا توجد فروق ذات دلالة إحصائية بين درجات المجموعة التجريبية في التطبيق القبلي

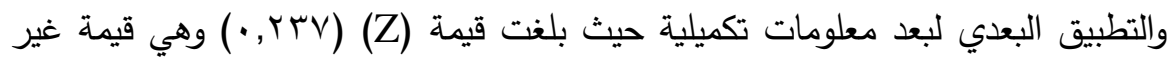

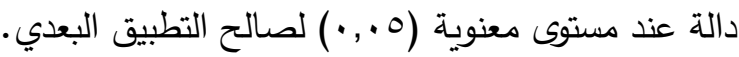
> توجد فروق ذات دلالة إحصائية بين درجات المجموعة التجريبية في التطبيق القبلي

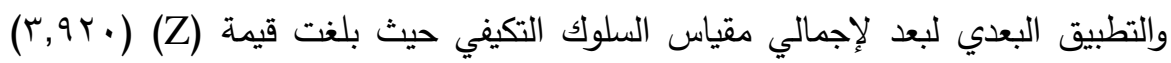
وهي قيمة دالة عند مستوى معنوية (0. . • ) لصالح التطبيق البعدي. لصني. مما سبق تحقق صحة الفرض الأول: توجد فروق دالة إحصائيًا في درجة التكيف السلوكي لأطفال العينة على مقياس السلوك التكيفي قبل وبعد تطبيق البرنامج. الفرض الثاني: لا توجد فروق دالة إحصائيًا في درجة التكيف السلوكي لأطفال العينة على مقياس السلوك التكيفي في التطبيق البعدي والتتبعي. 
مجلة العلوم البيئية

معهد الدراسات والبحوث البيئية - جامعة عين شمس لبنه

رنا عصام حامد السمّان وآخرون

جدول(ץ): نتائج اختبار (ويلكوكسون) لحساب الفروق بين درجات التكيف السلوكي لأطفال العينة على مقياس السلوك التكيفي في التطبيق البعدي والتتبعي.

\begin{tabular}{|c|c|c|c|c|c|c|}
\hline \multirow{2}{*}{ مستوى الدلالة } & \multirow{2}{*}{$(\mathrm{Z})$} & \multicolumn{2}{|c|}{ التطبيت التبعى (r. } & \multicolumn{2}{|c|}{ 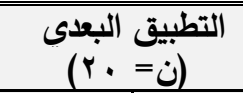 } & \multirow{2}{*}{ المتغيرات } \\
\hline & & الرتب مجوع & متوبط الرتب & الرتب مجوع & متوبط & \\
\hline r , • غير دالة & $1, \varepsilon 1 \leqslant$ & $r, \ldots$ & $1,0$. & $\cdot, \cdots$ & $\bullet, \cdots$ & السلوك المدمر \\
\hline r, • غير دالة & $1, \varepsilon) \leqslant$ & $r, \ldots$ & $1,0$. & $\cdot, \cdots$ & $\cdot, \cdots$ & السلوك المضتاد \\
\hline r, • غير دالة & $1, \cdots$ & $1, \cdots$ & $1, \ldots$ & $\cdot, \cdots$ & $\cdot, \cdots$ & سلوك التمرد \\
\hline • , , غير دالة & $\cdot, \cdots$ & $\cdot, \cdots$ & $\cdot, \cdots$ & $\cdot, \cdots$ & $\cdot, \cdots$ & سلوك لا يوثق به \\
\hline r, • غير دالة & $1, \leqslant 1 \leqslant$ & $r, \ldots$ & $1,0$. & $\cdot, \cdots$ & $\cdot, \cdots$ & الإنسحاب \\
\hline • , أير دالة & $\cdot, \cdots$ & $\cdot, \cdots$ & $\cdot, \cdots$ & $\cdot, \cdots$ & $\cdot, \cdots$ & واللزمات الغربية النمطي \\
\hline r, • غير دالة & $1, \cdots$ & $1, \cdots$ & $1, \cdots$ & $\cdot, \cdots$ & $\cdot, \cdots$ & السلوك العلاقات مناسب \\
\hline ז, • غير دالة & $1, \cdots$ & $1, \cdots$ & $1, \ldots$ & $\cdot, \cdots$ & $\cdot, \cdots$ & عادات صبوتية غير \\
\hline • , أير دالة & $\cdot, \cdots$ & 1,0 & 1,0 & 1,0 & $1,0$. & عادات غير مقبولة \\
\hline · , غير دالة & $\cdot, \cdots$ & $\cdot, \cdots$ & $\cdot, \cdots$ & $\cdot, \cdots$ & $\cdot, \cdots$ & سلوك يؤذي النفس \\
\hline . , غير دالة & $\cdot, \cdots$ & $\cdot, \cdots$ & $\cdot, \cdots$ & $\cdot, \cdots$ & $\cdot, \cdots$ & الميل للحركة الزائدة \\
\hline r, • غير دالة & $1, \cdots$ & $1, \ldots$ & $1, \ldots$ & $\cdot, \cdots$ & $\cdot, \cdots$ & السلوك الشاذ جنسياً \\
\hline r , • غير دالة & $1, \leq 1 \leq$ & $\cdot, \cdots$ & $\cdot, \cdots$ & $r, \ldots$ & $1,0$. & 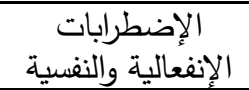 \\
\hline . , غير دالة & $\cdot, \cdots$ & $\cdot, \cdots$ & $\cdot, \cdots$ & $\cdot, \cdots$ & $\cdot, \cdots$ & معلومات تكميلية \\
\hline r , • غير دالة & $1, \sum\lceil\wedge$ & $v, \ldots$ & $07, \cdots$ & $r r, \cdot$ & 0,0 . & إلسمالى مقياس التكيفى \\
\hline
\end{tabular}

اتضح من الجدول السابق لحساب دلالة الفروق بين درجات المجموعة التجريبية في التطبيق البعدي والتطبيق التتبعي لمقياس السلوك التكيفي: عدم وجود فروق ذات دلالة

الترقيم الدولي 0826-1110 
إحصائية بين درجات المجموعة التجريبية في التطبيق البعدي والتطبيق التتبعي لمقياس السلوك التكيفي حيث كانت قيم (Z) غير دالة عند مستوى معنوية (0 . . •).

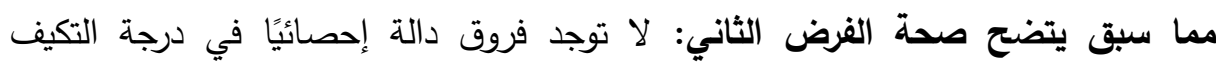

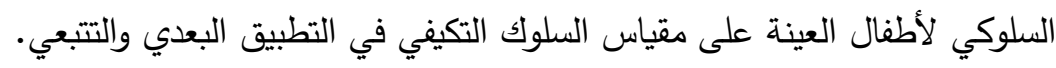
الفرض الثالث: توجد فروق دالة إحصائيًا في درجة التكيف السلوكي لأطفال العينة بين المجموعة الضابطة والمجموعة التجريبية على مقياس السلوك التكيفي في التطبيق البعدي. جدول(؛): نتائج اختبار (مان ويتتي) لحساب الفروق بين درجات المجموعة الضابطة والمجموعة التجريبية في التطبيق البعدي لمقياس السلوك التكيفي

\begin{tabular}{|c|c|c|c|c|c|c|}
\hline \multirow{2}{*}{ 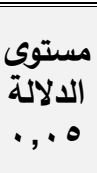 } & \multirow{2}{*}{$(\mathrm{Z})$} & \multicolumn{2}{|c|}{ 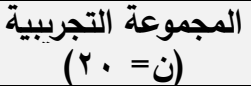 } & \multicolumn{2}{|c|}{ 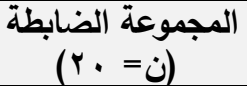 } & \multirow{2}{*}{ المتغيرات } \\
\hline & & الزتبوع & متوسط الرتب & مجموع & متوسط الرتب & \\
\hline$\cdot, 9$ & $\cdot, \wedge \vee$. & ह17,. & $r \cdot, \Lambda$. & $\varepsilon \cdot \varepsilon, \cdot$ & $r_{\cdot, r_{.}}$ & السلوك المدمر والعنيف \\
\hline$\cdot, 9$ &., $9 \leqslant 7$ & $\varepsilon \cdot v, 0$ & $r \cdot, r \Lambda$ & $\varepsilon \backslash Y, 0$ & $r \cdot, T r$ & السلوك المضاد للمجتمع \\
\hline$\cdot, r$ & $\cdot, r \cdot \Lambda$ & $r V Y, 0$ & 11,74 & $\varepsilon \leqslant \vee, 0$ & rY,rA & سلوك التمرد \\
\hline$\cdot, 7$ &., $0 \mathrm{OT}$ & 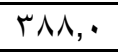 & $19, \varepsilon$ & $\varepsilon r r_{,}$ & $Y, Y$. & سلوك لا يوثق به \\
\hline$\cdot, 7$ & $\cdot, 7,7$ & 491,0 & 19,01 & $\sum r \wedge, 0$ & Y I, $\leqslant r$ & الإنسحاب \\
\hline$\cdot, 9 \mathrm{~V}$ & $\cdot, \cdot \leqslant r$ & $\varepsilon \cdot \wedge, 0$ & $r \cdot, \Sigma T$ & $\leqslant 11,0$ & $r \cdot, 0 \Lambda$ & السلوك النمطي واللزمات الغريبة \\
\hline$\cdot, \mathrm{V}$ & $\cdot, \varepsilon \leqslant V$ & $r q \varepsilon, 0$ & $19, \mathrm{Vr}$ & $\leqslant Y 0,0$ & $r I, r \wedge$ & السلوكات غير مناسب فئى \\
\hline$\cdot, 9$ & $\cdot, \cdot v$. & $\sum \backslash,, 0$ & $r \cdot, T r$ & $\varepsilon \cdot V, 0$ & $r \cdot, r \Lambda$ & عادات صوتية غير مقبولة \\
\hline., 0 & $\cdot ., 7 \times 1$ & $r \wedge 0,0$ & $19, Y \wedge$ & $\varepsilon r \varepsilon, 0$ & $r I, V \mu$ & عادات غير مقبولة أو شاذة \\
\hline$\cdot, r$ & $1, .7 \mathrm{~V}$ & TVY,. & $1 \wedge, 7$ & $\varepsilon \Sigma \wedge, \cdot$ & YY, & سلوك يؤذي النفس \\
\hline$\cdot, \Gamma$ &., 999 & $r v v^{\prime}$ & $1 \wedge, \wedge 0$ & $\varepsilon \leqslant \Gamma$, & $r Y, 10$ & الميل للحركة الزائدة \\
\hline$\cdot, Y$ & $1,1 \vee r$ & $\varepsilon \leqslant\rceil$, & $r Y, r$. & $r v \varepsilon$, & $1 \wedge, \vee$. & السلوك الثاذ جنسياً \\
\hline$\cdot, \wedge$ & $\cdot, Y \vee I$ & $\varepsilon \cdots, \cdot$ & $r \cdot, \cdots$ & $\Sigma Y \cdot, \cdot$ & $r 1, \ldots$ & الإضطرابات الإنفعالية والنفسية \\
\hline$\cdot, \wedge$ & $\cdot, r 91$ & $\varepsilon r \cdot, 0$ & $r 1, \cdot r$ & $r q 9,0$ & 19,91 & معلومات تكميلية \\
\hline$\cdot, 7$ & $\cdot, \leqslant 7$. & rqr,. & 19,70 & $\varepsilon r V,$. & Yl, ro & إجمالي مقياس السلوك التكيفي \\
\hline
\end{tabular}


اتضح من الجدول السابق لحساب دلالة الفروق بين درجات المجموعة الضابطة والمجموعة التجرببية في التطبيق البعدي لمقياس السلوك التكيفي ما يلي:

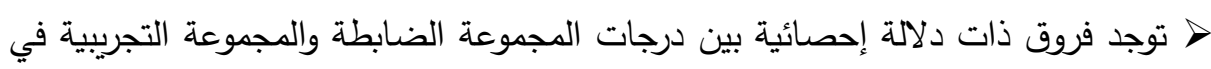

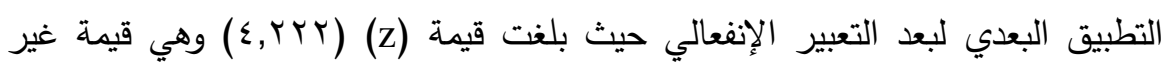

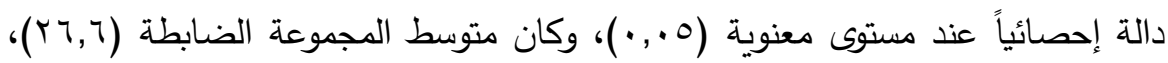

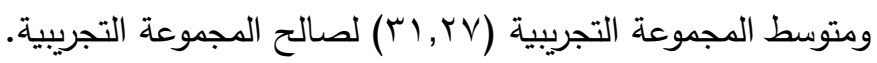

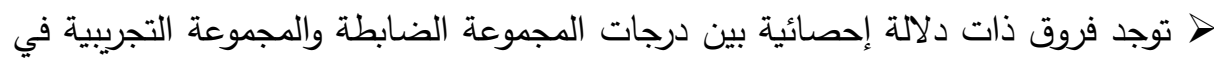

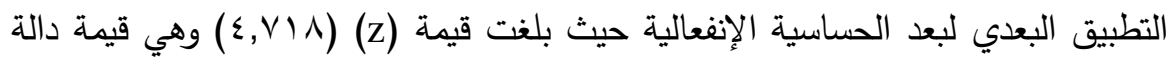

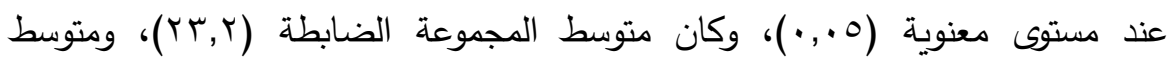
المجموعة التجريبية (r, § r) لصالح المجموعة التجريبية.

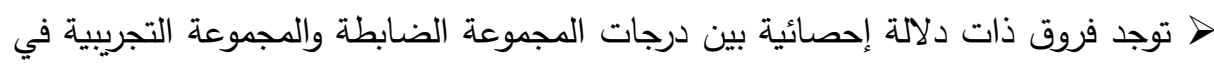

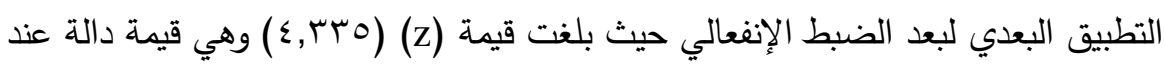

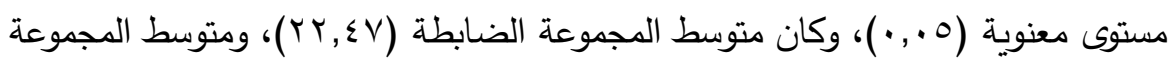

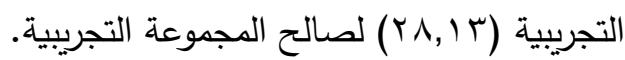
> توجد فروق ذات دلالة إحصائية بين درجات المجموعة الضابطة والمجموعة التجريبية في

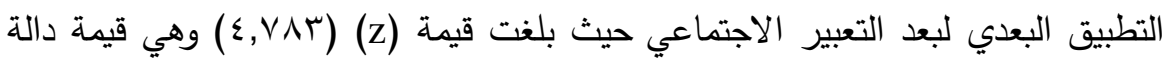

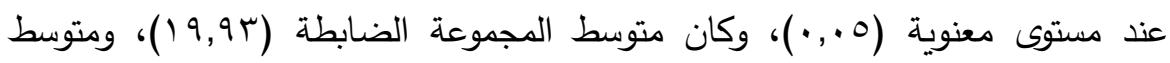
المجموعة التجريبية ( . , اءع) لصالح المجموعة التجريبية. > توجد فروق ذات دلالة إحصائية بين درجات المجموعة الضابطة والمجموعة التجريبية في

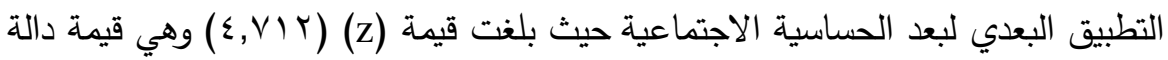

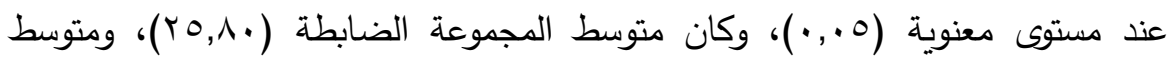

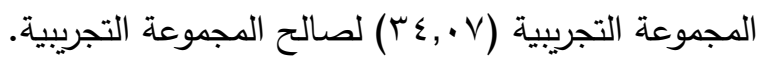

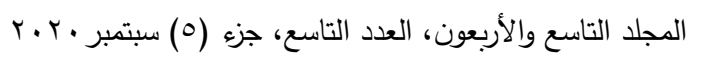


توجد فروق ذات دلالة إحصائية بين درجات المجموعة الضابطة والمجموعة التجريبية في

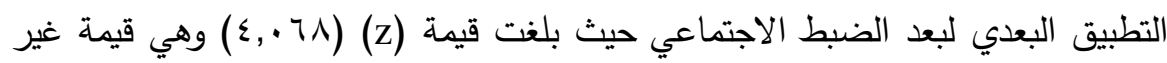

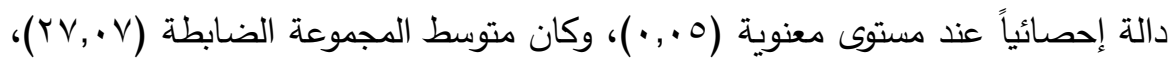

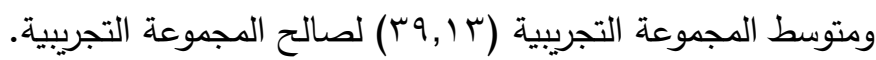
توجد فروق ذات دلالة إحصائية بين درجات المجموعة الضابطة والمجموعة التجريبية في

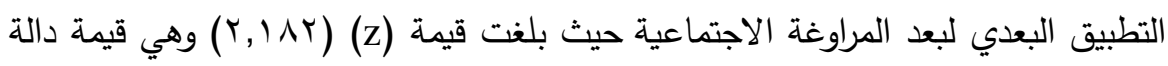

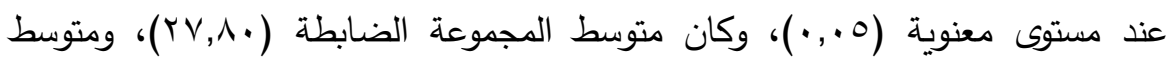

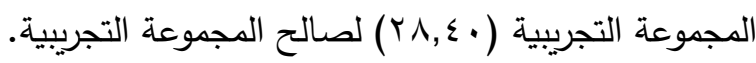
توجد فروق ذات دلالة إحصائية بين درجات المجموعة الضابطة والمجموعة التجريبية في

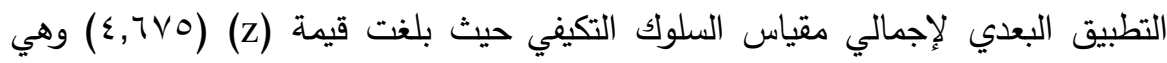

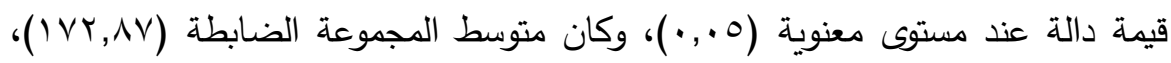
ومتوسط المجموعة التجريبية (ب, جr,Or) لصالح المجموعة التجريبية. مما سبق تحقق صحة الفرض الثالث: توجد فروق دالة إحصائيًا في درجة التكيف السلوكي

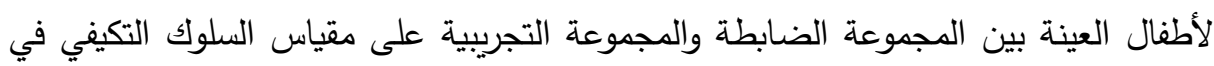
التطبيق البعدي.

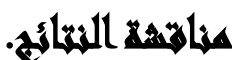

ا ـ توجد فروق دالة إحصائيًا في درجة التكيف السلوكي لأطفال العينة على مقياس السلوك التكيفي قبل وبعد تطبيق البرنامـج.

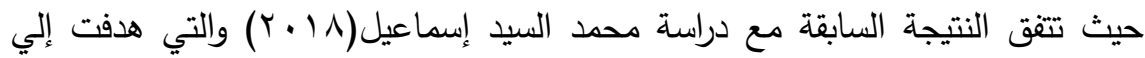
استخدام برنامج منتسوري لتحسين مهارات السلوك التكيفي لدي عينة من الأطفال ذوي الإعاقة الذهنية البسيطة، حيث أشارت الدراسة إلي تحسن مهارات الرعاية الذاتية لدي هؤلاء الأطفال. 


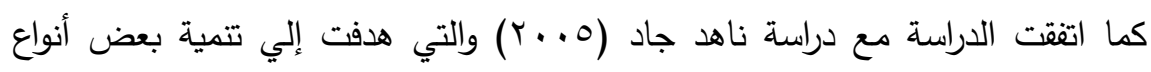

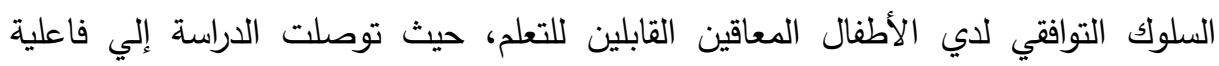
البرنامج في تتمية مهارات التوافق لدي هؤلاء الأطفال.

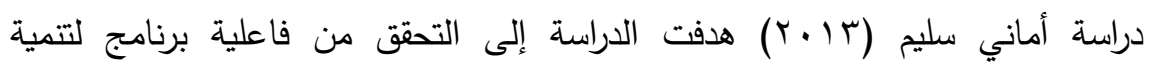
الاستقلالية قائم على فلسفة منتسوري التربوية لاى عينة من الأطفال ذوي الإعاقة العقلية

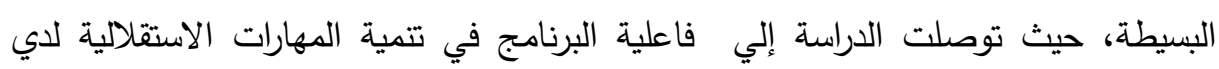
الأطفال المعاقين ذهنيا.

كما قدم البرنامج أنشطة حركية للأطفال المعاقين ذهنيا، وقد كان هناك إقبال عليه من

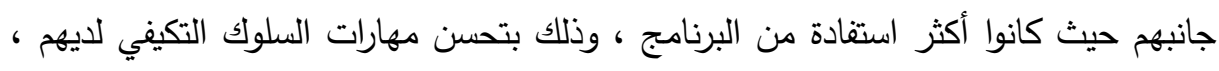
لذا كانت النتائج لصالحهم بعد تطبيق جلسات البرنامج. كما تفسر الباحثة هذه النتيجة للتحسن الذي طرأ علي أفراد المجموعة التجريبية إلي الالتزام من قبل أفراد المجموعة التجريبية في الحضور والمشاركة في الأنشطة وجلسات

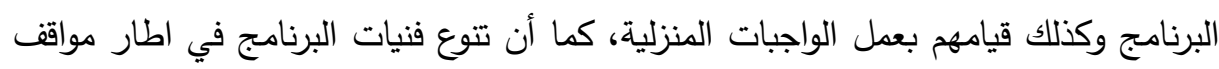

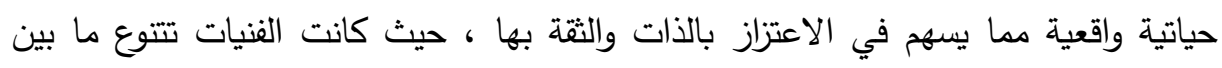

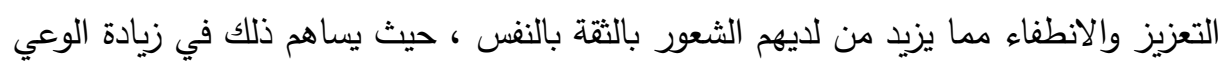

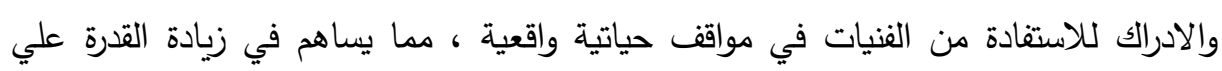

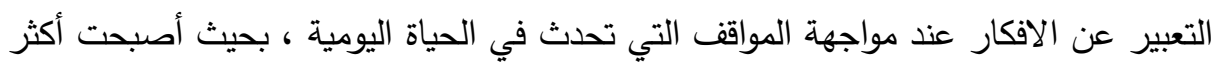

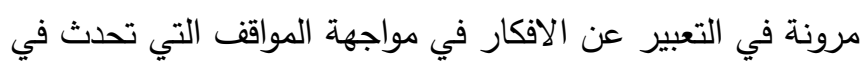

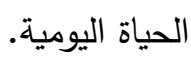

أيضا ترجع الباحثة تفسير النتيجة السابقة إلي فاعلية استراتيجيات البرنامج المقدم للأطفال :

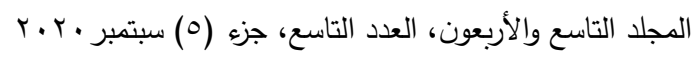

$$
\begin{aligned}
& \text { الترقيم الدولي 0826-08 1110 }
\end{aligned}
$$


حيث تم استخدام استراتيجيات تتاسب الأطفال المعوقين عقلياً، وهي استراتيجيات تعديل

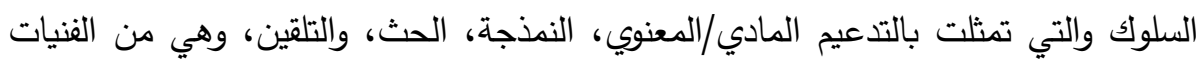
الفعالة مع الأطفال المعوقين عقلياً القابلين للتعليم. نظراً لاستخدام أنشطة متتوعة في البرنامج ومنها اللعب، الذي يعد من الأنشطة المحبية إلى الطفل ويعد نشاطاً له جاذبيته الخاصة للمعوقين عقلياً لما يمنحه من شعور بالمشاركة الفائه والفاعلية والمنافسة والتشجيع والرضا والسعادة، ويشكل وسطاً جيداً لتعليمهم كثيراً من المفاهيم

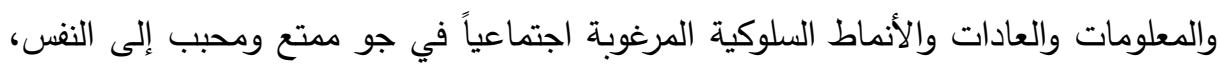
ويتعلم الأطفال عن طريق اللعب الكثير عن العالم، والحياة، والناس فيكتسبون المهارات المتتوعة.

ومن العوامل التي ساعدت في نجاح البرنامج أن الباحثة عند بناء البرنامج راعت

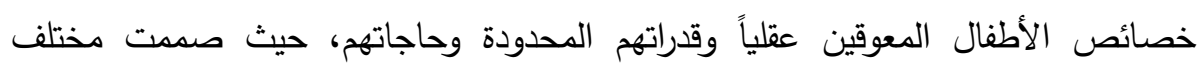

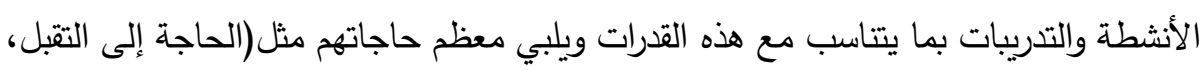

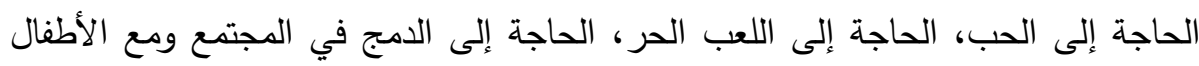

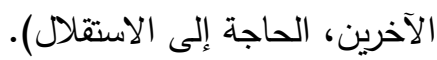
أيضا يمكننا تفسير ذلك في ضوه النظرية السلوكية والتي تتظر إلي حالات الإعاقة

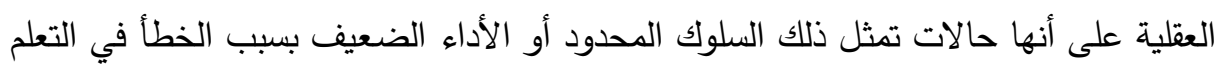

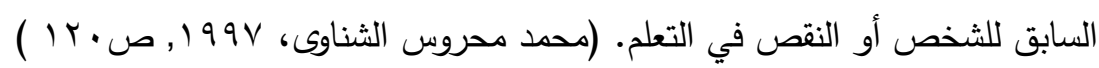
حيث أن النظرية ترجع الفرق في الأداء بين الطفل العادي والطفل المعاق عقليا يرجع

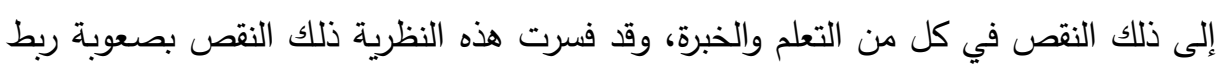

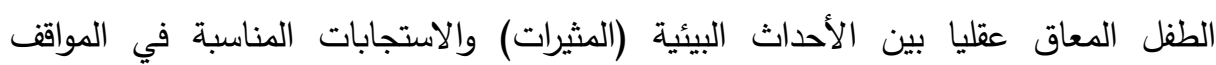
المناسبة، ولذا فحسب هذه النظرية يلعب التعزيز دورا مهما في تعديل سلوك الأطفال المعاقين

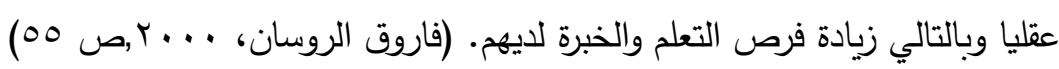




$$
\begin{aligned}
& \text { مجلة العلوم البيئية } \\
& \text { معهد الدراسات والبحوث البيئية - جامعة عين شمس به } \\
& \text { رنا عصام حامد السمّان وآخرون }
\end{aligned}
$$

r. لا توجد فروق دالة إحصائيًا في درجة التكيف السلوكي لأطفال العينة على مقياس السلوك التكيفي في التطبيق البعدي والتتبعي.

وبذلك يتحقق صحة الفرض الثاني للدراسة الحالية حيث أنه لا توجد فروق دالة إحصائيًا في درجة التكيف السلوكي لأطفال العينة على مقياس السلوك التكيفي في التطبيق البعدي والتتبعي.

وهو ما يتفق مع دراسة تركية الطويرقي (r + r): والتي هدفت إلي إمكانية استخدام

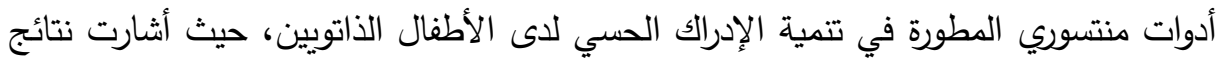
الدراسة إلي أنه لا توجد فروق دالة إحصائياً بين متوسطات رتب درجات الأطفال في القياسين

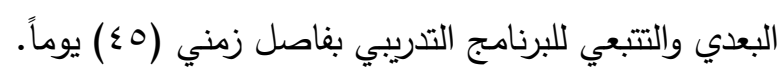
مما يدل علي استمرارية تأثير البرنامج التدريبي وفاعلية فترة المتابعة في تحسين مهارات السلوك التكيفي، وتفسر الباحثة استمرار تأثير وفعالية البرنامج وذلك لقدرة أفراد العينة علي استغلال الأنشطة والخبرات التي تم اكتسابها وتعليمها في البرنامج كوسيلة نافعة في تتمية مهارات السلوك التكيفي وذلك من خلال تكوين مفاهيم ايجابية لديهم وذلك ساعد في

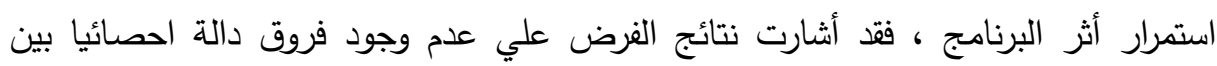

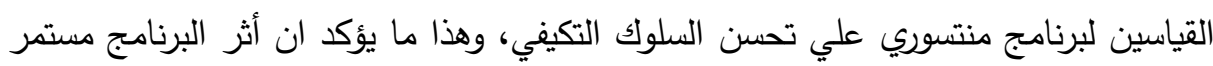

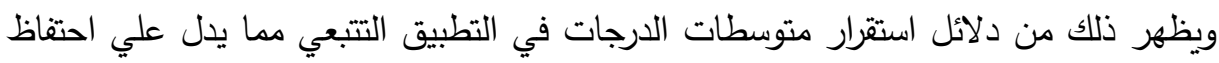
هؤلاء الأطفال لمستوي سلوكهم التكيفي لديهم والتي كان عليها بعد الانتهاء من تقديم البرنامج

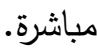
كما يمكن إرجاع ذلك لما حصل عليه الأطفال من تقدم داخل الجلسات البرنامج والتي

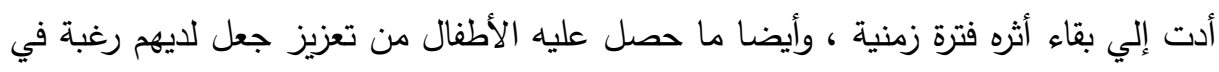

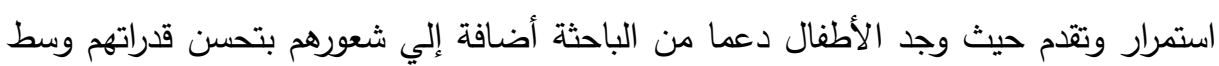
جماعة الأقران.

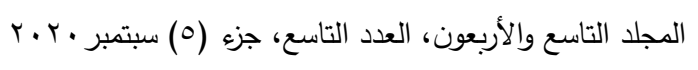


وهذا يعني أن البرنامج أسهم في تحسين أداء أفراد المجموعة التجريبية في مستوي

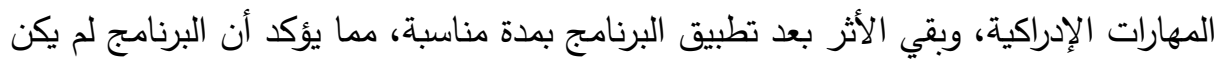

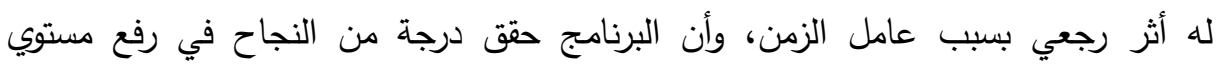
المهارات الإدراكية.

كما أن التدريب المستمر على كل نثاط من الأنشطة إضافة إلى التكرار، لأن الطفل

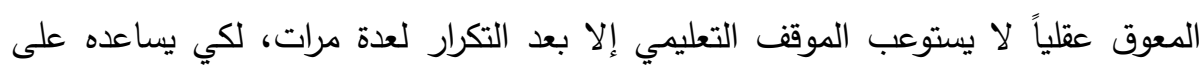
التذكر والاستفادة من مواقف التعلم. التدعيم حيث كان التدعيم يقدم عند نجاح الطفل بأداء كل مهمة من المهام المطلوبة منه، وهذا كان يدفعه إلى أداء المطلوب منه حتى يحصل على التدعيم، واستخدمت الباحثة التدعيم بنوعيه المادي والمعنوي.

الأنشطة والتدريبات التي استخدمت في البرنامج كانت من الأنشطة المحببة التي تجذب دئب

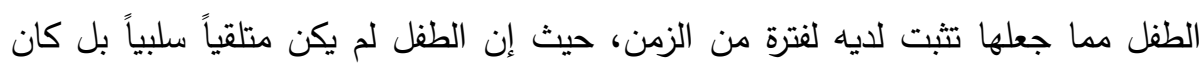
متلقياً إيجابياً وفعالاً وكان بحاجة إلى إيقاظ تلك المهارات وتتشيطها وتوظيفها.

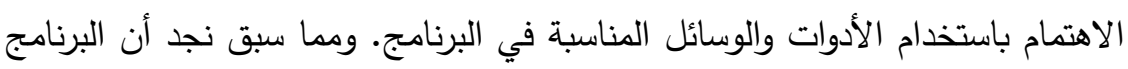

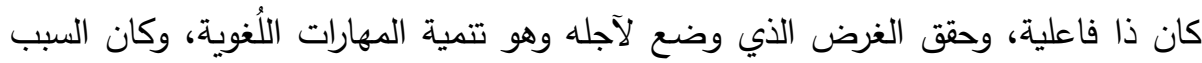

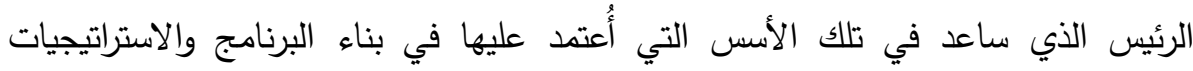
المستخدمة والخطوات التي اتبعت في تطبيقه، إضافة إلى مراعاة خصائص الفئة التي أُعد الند فئي

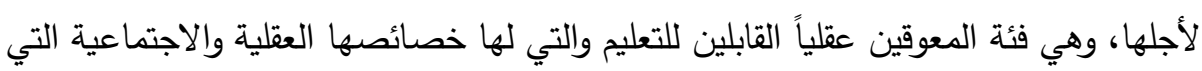
تميزها عن غيرها وتحتاج إلى استخدام الوسائل التي تتناسب معها.

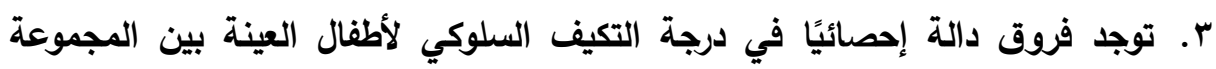
الضابطة والمجموعة التجريبية على مقياس السلوك التكيفي في التطبيق البعدي. 
وبذلك يتحقق صحة الفرض الثالث للدراسة الحالية توجد فروق دالة إحصائيًا في درجة التكيف السلوكي لأطفال العينة بين المجموعة الضابطة والمجموعة التجريبية على مقياس السلوك التكيفي في التطبيق البعدي. بتحقق صحة الفرض هذا يدل علي استمرارية تأثير البرنامج تطبيق الجلسات وهذا يحقق لفقائ

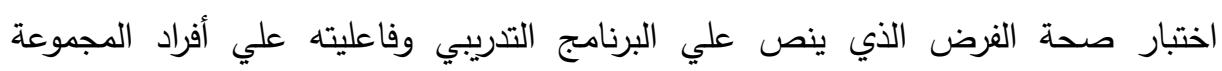

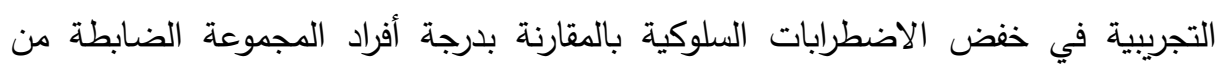

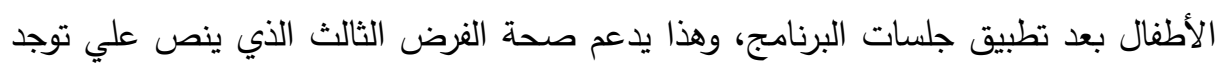

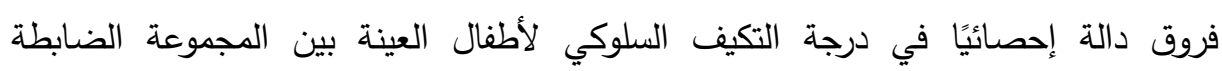
والمجموعة التجريبية على مقياس السلوك التكيفي في التطبيق البعدي.

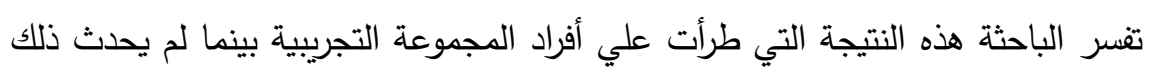
لأفراد المجموعة الضابطة إلي التزام أفراد المجموعة التجريبية في الحضور والمشاركة في لتئي

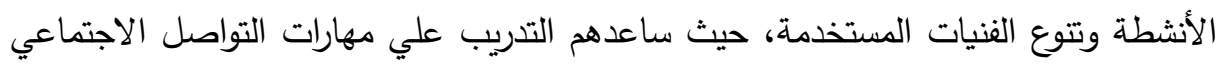

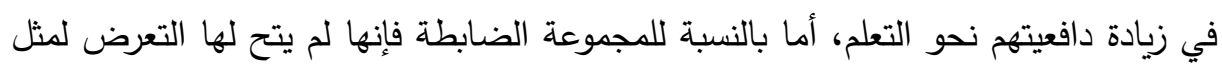
تلك الأنشطة المختلفة التي تضمنها البرنامج الذي تعرض لهاته أفراد المجموعة التجريبية. وتفسر الباحث ذلك من خلال:

التدريب المستمر علي كل نشاط من الأنثطة إضافة إلي التكرار، لأن الطفل المعاق

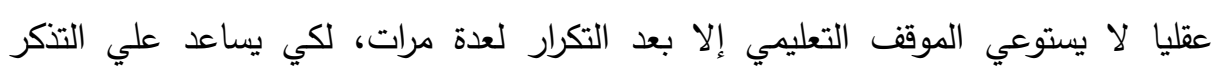
والاستفادة من مواقف التعلم. كما أن الأنشطة التي استخدمت في البرنامج كانت من الأنشطة المحببة التي تجذب لمبن

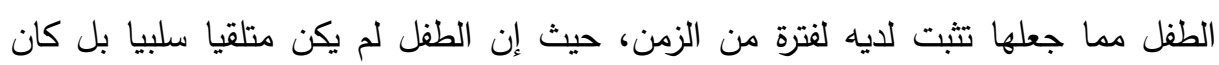

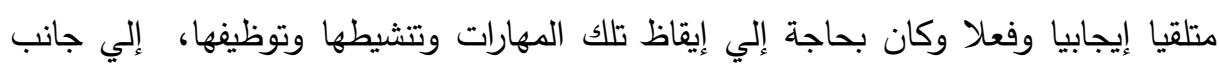
الاهتمام باستخدام الأدوات والوسائل المناسبة في البرنامج. إليعان

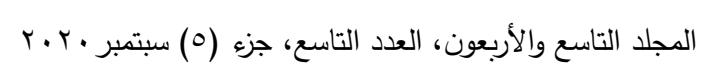


مما سبق نجد أن البرنامج كان ذا فاعلية، وحقق الغرض الذي وضع من أجله، وهو

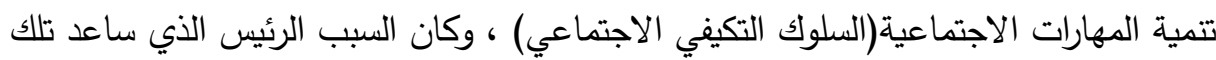

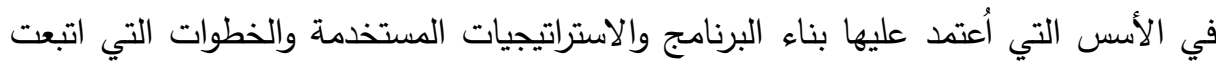
في تطبيقه.

إضافة إلي مراعاة خصائص الفئة التي أعد لأجلها، وهي فئة الأطفال ذوي الإعاقة العقلية الذهنية البسيطة، القابلين للتعلم والتي لها خصائصها العقلية والاجتماعية التي تميزها عن غيرها وتحتاج إلي الوسائل التي تتناسب معها. كما ترجع الباحثة ظهور أثر البرنامج إلي الاستراتيجيات المستخدمة حيث تهني تم استخدام استراتيجيات تتناسب مع الأطفال ذوي الإعاقة الذهنية البسيطة، وهي استراتيجيات تعديل

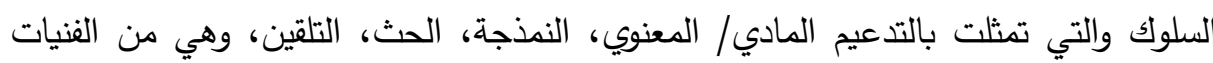
الفعالة مع الأطفال المعاقين ذهنيا. إلي جانب أستخدم أنشطة متتوعة في البرنامج منها اللعب والذي يعد من الأنشطة المحببة إلي الطفل، ويُعد نشاطا له جاذبيته الخاصة للمعاقين ذهنيا، لما يمنحه من شعور لئه بالمشاركة والفاعلية والمنافسة والتثجيع والرضا والسعادة، ويشكل وسطا جيدا لتعليمه كثيرا

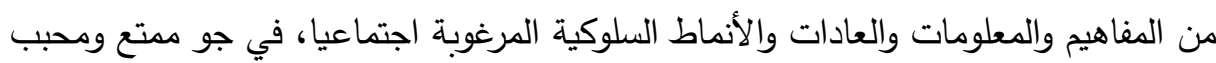
إلي النفسي، ويتعلم الأطفال عن طريق اللعب الكثير عن العالم والحياة، والناس فيكتسبون المهارات المتنوعة.

أيضا من العوامل التي ساعدت في نجاح البرنامج أن الباحثة عند بناء البرنامج راعت

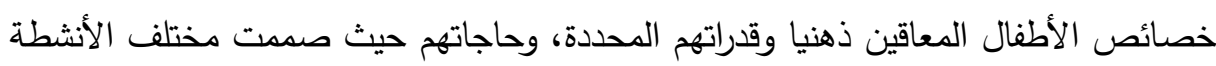
والتدريبات بما يتاسب مع هذه القدرات، ويلبي معظم حاجاتهم مثل ( الحاجة إلي التقبل،

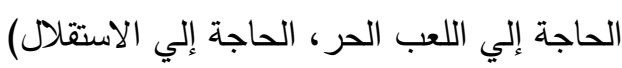

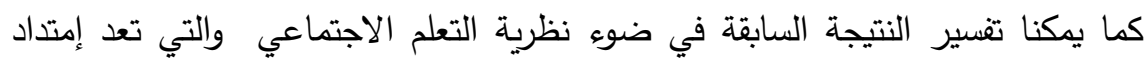
للتعلم بالتقليد أو النمذجة، إذ تثترك هذه النظريات في التركيز على أهمية التفاعل الإجتماعي فئي 210

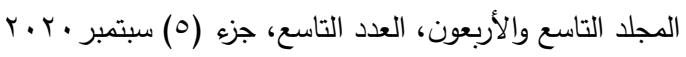

$$
\begin{aligned}
& \text { الترقيم الدولي 0826-1110 }
\end{aligned}
$$


بين الفرد ومجتمعه، ويعني ذلك أن التعلم وفق هذه النظرية يتم من خلال التفاعل الإجتماعي،

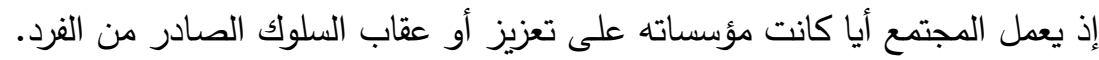

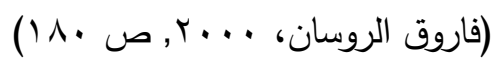

ويمكن توظيف هذه النظرية في ميدان الإعاقة العقلية وذلك لبناء البيئة الإجتماعية التي يتم فيها التدريس، إذ يجب أن يعمل معلم التربية الخاصة على توفير كل الفرص أمام الطفل

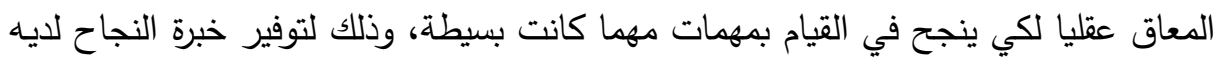

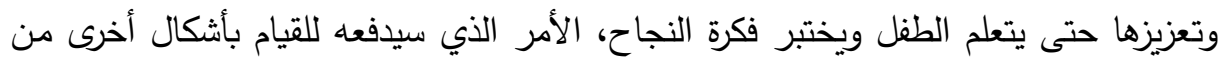
السلوكيات الناجحة فيما بعد وفي مهمات تعليمية لاحقة.

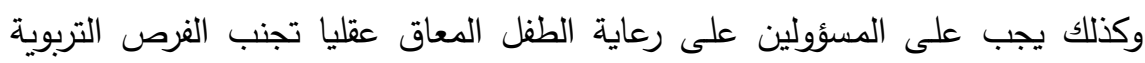
التي يفشل فيها الطفل وذلك لإبعاد خبرة الفشل لديه، خاصة وأن معظم أشكال التعلم لديه فاشلة في بداية التعلم، إذ أن خبرة الفشل المتكررة تؤدي إلى الإنسحاب في المواقف التعليمية، لإدهاد

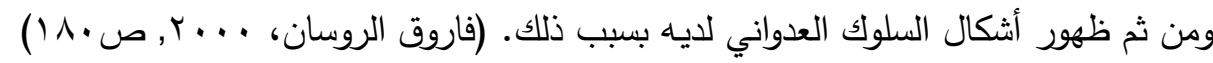

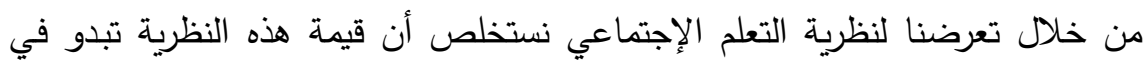

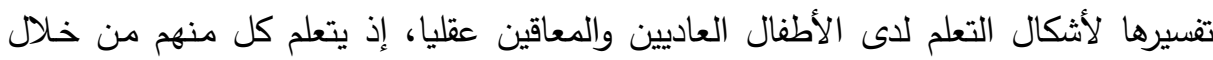

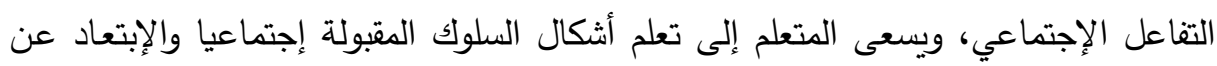
أشكال السلوك غير المقبولة إجتماعيا، ولذلك فعلى المشرفين على رعاية الطفل المعاق عقلئ إنليا أن يضعوا أمامه فرص النجاح للقيام بمهمات معينة، وتجنب كل الفرص التي تؤدي إلى

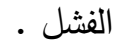

من خلال ما سبق نستخلص أن نظريات التعلم لها علاقة وثيقة بميدان تعديل السلوك، إذ يتمثل مفهوم التعلم في إحداث تغير في سلوك الفرد تحت شروط الممارسة والتكرار والخبرة، ويمكن تفسير ذلك التغير بعدد من نظريات التعلم، وفي الوقت نفسه فإن مفهوم تعديل

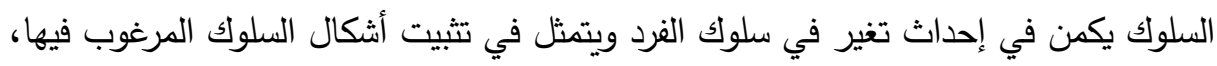

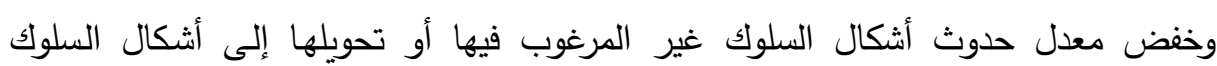

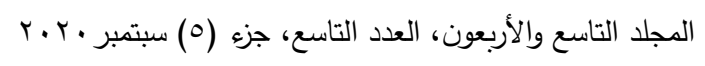

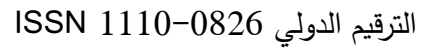


المرغوب فيها وفق عدد من الإستراتيجيات، ويعني ذلك أن كلا من الموضوعين أي موضوع تعديل السلوك وموضوع التعلم يدرسان التغير في السلوك الإنساني، ويهدف كل منهما إلى دئى إحداث ذلك التغير المطلوب في السلوك الإنساني إعتمادا على توظيف كل منهما للمفاهيم الأساسية والمبادئ والإستراتيجيات التي يتضمنها موضوع التعلم. أيضا تتقق النتيجة السابقة مع ما جاء في النظرية السلوكية والتي تؤكد أن السلوك

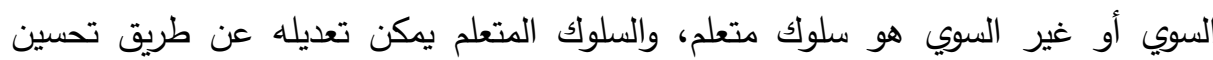

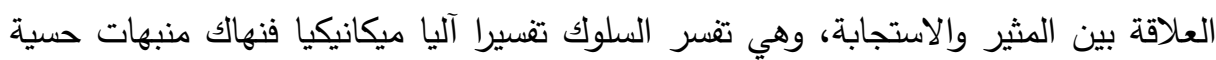
وحركية( مثير) تثير سلسلة من الافعال المنعكسة لدي الكائن الحي( استجابة) وتربط تلكئل

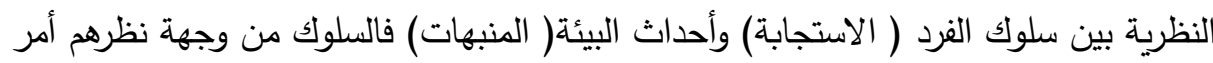

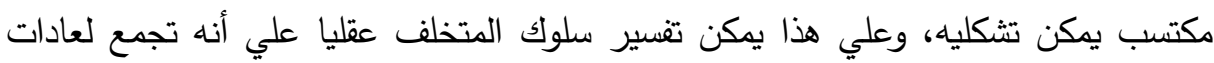

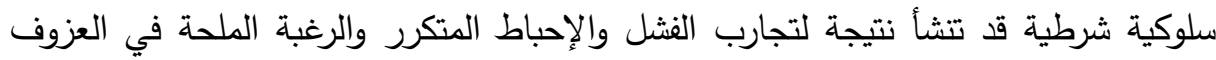

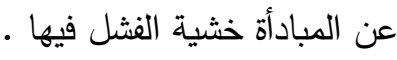

وتري الباحثة أن السلوك من وجهة نظر السلوكيين أمر مكتسب، يمكن تعديله وتغييره حينما يستطيع الكائن الحي تكوين روابط بين المثير والاستجابة والتي يتقق عرض ارتباطها

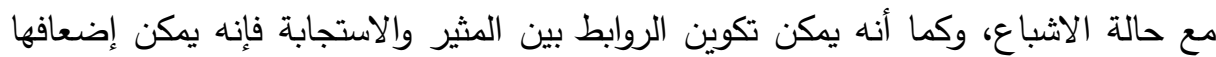

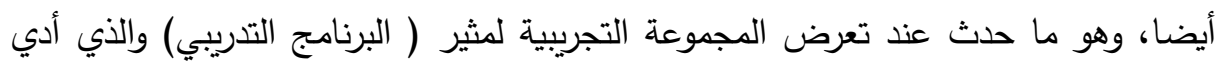
الي تعديل بعض السلوكيات اللا تكيفية لايهم، علي عكس المجموعة الضابطة والتي لم تتعرض لمثير قبل وبعد تطبيق البرنامج، فجاءت النتيجة لصالح المجموعة المطبق عليها

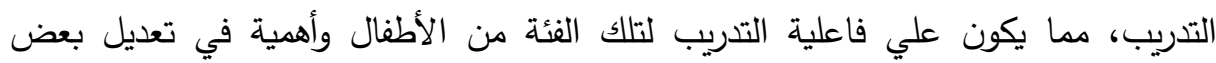

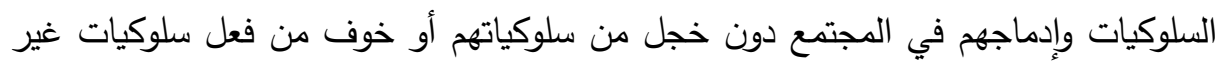
مقبولة اجتماعيا. اهم التوصيات التي خرجت بها الاراسة: 1-أن توفر المؤسسات الحكومية الأدوات اللازمة لتتمية مهارات الأطفال ذوي الإعاقة.

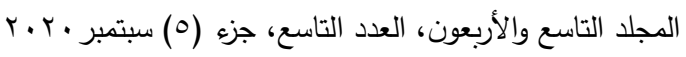

$$
\begin{aligned}
& \text { ISSN 1110-0826 الترقيم الدولي }
\end{aligned}
$$


ץ-يجب إرسال متخصصين لتعليم العاملين في مؤسسات رعاية ذوي الإعاقة الذهنية كل ما هو جديد في هذا المجال. r- لا بد من التقتيش المفاجئ علي مؤسسات رعاية ذوي الاحتياجات الخاصة لضبط العمل. ع-توفير ميزانية خاصة في إدارة كل مؤسسة لغير القادرين ماديا. 0- توفير مساحة للتريض يوميا داخل أو بجانب كل مؤسسة.

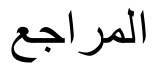

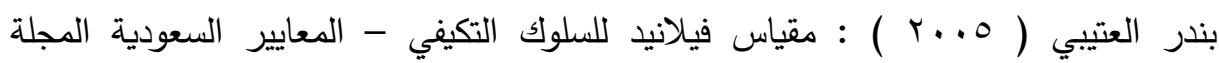

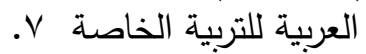

$$
\text { الجهاز المركزي للتعبئة والاحصاء(Y) }
$$

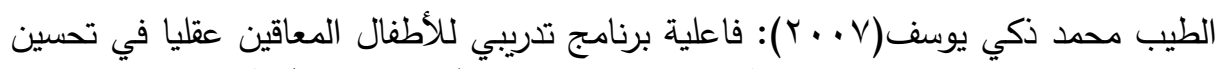
بعض مهاراتهم التعليمية, راسة ماجستير (غير منشورة),كلية البنات, جامعانة عين شمس.

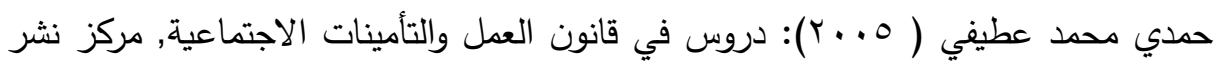

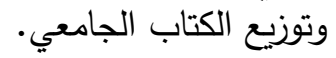

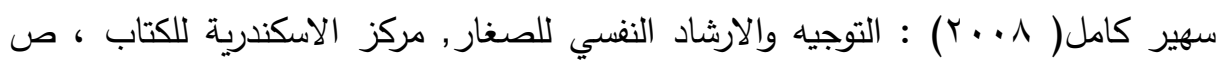
$(\wedge r$

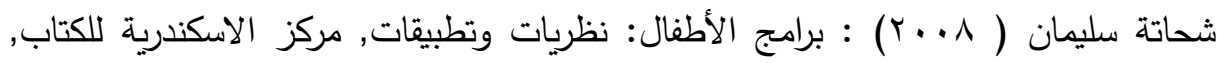

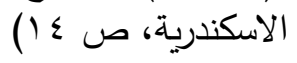

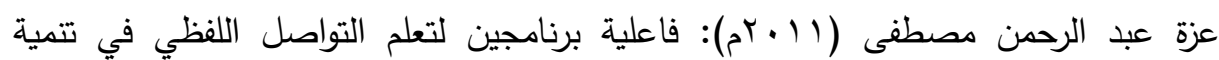

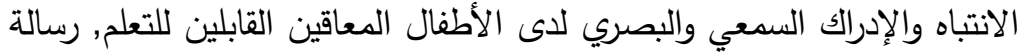

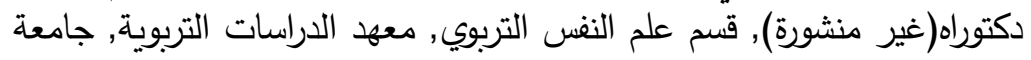
القاهرة.

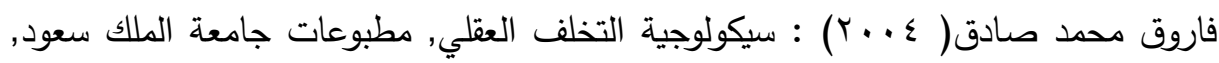

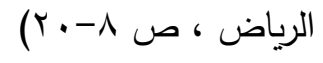

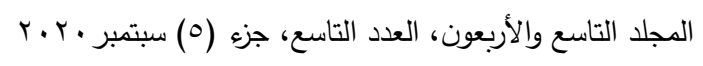




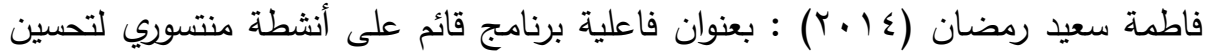

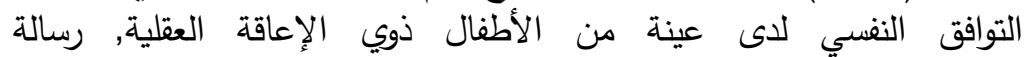
ماجستير (غير منشورة), كلية التربية, جامعة عين شمس.

ماجدة عبيد ( . . . . ) ) تعليم الأطفال المتخلفين عقليًا. عمان: دار صفا للنشر والتوزيع. محمد السيد إسماعيل (1) (Y): بعنوان فاعلية برنامج قائم على طريقة منتسوري لتحسين

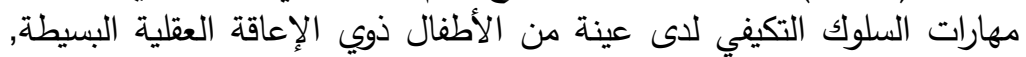

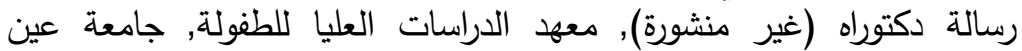
شمس.

محمود رامز يوسف (T ( ا Y): بعنوان فاعلية برنامج قائم على طريقة منتسوري لتحسين

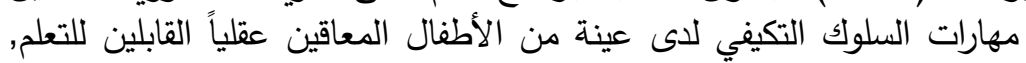
رسالة ماجستير, قسم الصحة النفسية والارشاد النفسي, كلية التربية, جامعة الإنة عين شمس. منظمة الصحة العاليمة(r ( • r): العجز , المكتب الأقليمي لشرق المتوسط.

Belchic , J,(1995): Stress, social support, and sense of parenting competence: A comparison of mothers and father of children with autism, down syndrome, and normal development across te family life cycle. unpublished master thesis, the state univerersity, new Jersey .

Dabrowska A Pisula E ( 2010). Parenting stress and styles in mothers and fathers of Pre-school children with Autism and Downsyndrome, Jozef Piludski university of physical education in warsaw, warsaw, Poland.

Hardiman, Sharon; Guerin, Susan; Fitzimons, Elaine (2009): A Comparison of Social Competence of Children with Moderate Intellectual Disability in Inclusive Versus Segregated School Settings. Research in Developmental

$$
\begin{aligned}
& \text { المجلد التاسع والأربعون، العدد التاسع، جزء (0) سبتمبر • r. } \\
& \text { الترقيم الدولي 0826-1110 }
\end{aligned}
$$




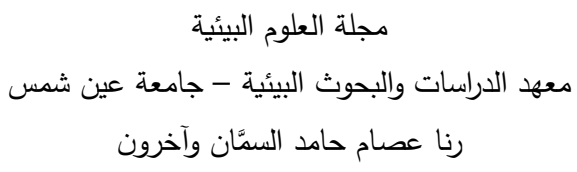

Disabilities: A Multidisciplinary Journal, Vol. (30), No. (2), pp. 397-407.

\title{
THE EFFECTIVENESS OF A COUNSELING PROGRAM BASED ON THE USE OF MONTESSORI \\ METHOD ON ADAPTIVE ENVIRONMENTAL BEHAVIOR IN A SAMPLE OF CHILDREN WITH MILD INTELLECTUAL DISABILITY
}

\author{
Rana E. H. El-Samaan ${ }^{(1)}$; Gamal S. Ahmed ${ }^{(2)}$ \\ and Abd El-Nabi A. Khater ${ }^{(3)}$ \\ 1) post grade, Institute of Environmental Studies \& Research, Ain \\ Shams University 2) Professor of Clinical Psychology, Faculty of Post \\ Graduate Childhood Studies, Ain Shams University 3) Vice-Dean of \\ the Institute of Social Work and Environment Affairs, Cairo.
}

\begin{abstract}
The present study aims to identify the effectiveness of a counseling program based on the use of the Montessori method on the environmental adaptive behavior in a sample of children with mild intellectual disabilities, identifying also the differences in the level of behavioral adaptation in a sample of children on the adaptive behavior scale pre/post application of the program. The researchers define a sample of (40) items, applied to a sample consisting of (40) children with mild intellectual disabilities, aged between (10-12) years, selected from boys, divided equally to (20) experimental samples and (20) control samples, from Al-Ghafir Foundation for people with special needs.
\end{abstract}

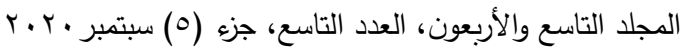

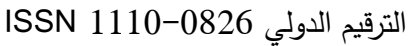




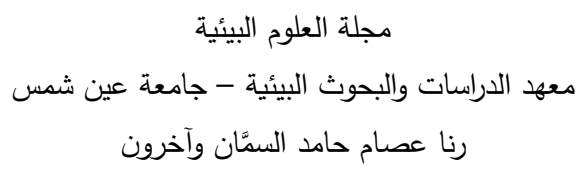

The researcher has used the (experimental) method and applied the scale of adaptive behavior. The research has come to several results, the most important of which is that there is a statistically significant correlation between the average scores of the control group and the experimental group, regarding the post application of the total adaptive behavior scale. There are statistically significant differences between the average scores of the experimental group, regarding the post/ follow up application of the adaptive behavioral scale. There are statistically significant differences between the average scores of the control group and the experimental group regarding the post-application of the total behavior scale, in favor of the experimental group. The research reached a set of recommendations, the most important of which are: the necessity of providing the necessary tools for developing skills for children with disabilities within government institutions, setting a special budget

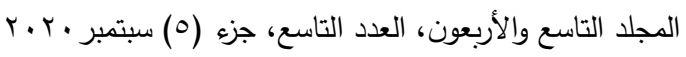

$$
\begin{aligned}
& \text { الترقيم الدولي 0826-1110 1SSN }
\end{aligned}
$$

